\title{
Dinámicas publicitarias en Argentina: una aproximación al caso de la Revista de la Asociación Médica Argentina (1914-1938)
}

\section{Advertising dynamics in Argentina: an approach to the case of the Journal of the Asociación Médica Argentina (1914-1938)}

\author{
María Dolores Rivero \\ Centro de Investigaciones y Estudios sobre Cultura y Sociedad, \\ Universidad Nacional de Córdoba, \\ Consejo Nacional de Investigaciones Científicas y Técnicas, Argentina \\ doloresriv@gmail.com
}

\begin{abstract}
Resumen
Indagamos en las dinámicas del ofrecimiento de medicamentos y aparatología terapéutica en la revista publicada por la Asociación Médica Argentina entre 1914 y 1938, periodo delimitado por el estallido de la Gran Guerra y la culminación del período de entreguerra, respectivamente.

Dichas dinámicas serán observadas a partir de la puesta en perspectiva de procesos político-económicos vinculados a las constantes mutaciones del concierto internacional, como el desarrollo industrial nacional en general, la puesta en marcha de la industria farmacéutica argentina, etc. En el plano local, atendemos a variables ligadas al potencial público consumidor de la publicación -los médicos- rescatando el proceso de profesionalización en el cual se hallaban inmersos y sus distintos estadios de consolidación como cuerpo profesional. Convergentemente, incluimos una aproximación a la trayectoria editorial de la revista en la cual se hallan insertas las publicidades, elemento insoslayable que también marcaría un derrotero particular del mercado bajo estudio. Partimos de considerar que ese mercado deviene en una muestra que permite observar cómo los fenómenos locales, nacionales e internacionales referidos anteriormente se entraman de forma compleja y variante.

Anclado en un abordaje de carácter cualitativo, nuestro aporte se define por rescatar y profundizar el valor heurístico y hermenéutico de las publicidades.
\end{abstract}

\section{Palabras clave}

Publicidades; medicamentos; aparatología terapéutica; Asociación Médica Argentina; Argentina. 


\title{
Dinámicas publicitarias en Argentina: una aproximación al caso de la Revista de la Asociación Médica Argentina (1914-1938)
}

\begin{abstract}
We inquire about the dynamics of the medicine and therapeutic equipment offer published in the journal of the Asociación Médica Argentina, between the years of 1914 and 1938, being this period framed by the Big War and the end of the interwar period.

These dynamics will be observed focusing in the point of view of political and economical processes, linked to the constant mutations of the international scene, like the national industrial development in general, the start up of the Argentinian pharmaceutical industry, and so on. In the local scene, we heed to the variables linked to the potential consumers of the publications - the practitioners- rescuing the professionalization process in which they were immerse and its different stages of the consolidation as a medical profession. We will include, as well, an approximation to the journal's editorial path, in which the advertisements are inserted, which is an unavoidable element that will indicate a particular track of the market that we are analyzing. We state that these market becomes a sample that allows us to observe how the local phenomena, the national as well as the international that we mention before, are tangled in a complex and changing way.

From the qualitative character, our contribution it aims to rescue and to fathom the heuristic and hermeneutic value of the advertisements.
\end{abstract}

\section{Keywords}

Advertisements; medicine; therapeutic equipment; Asociación Médica Argentina; Argentina.

\section{Introducción}

Los procesos de salud, enfermedad y prácticas de curar han ingresado en las agendas historiográficas adquiriendo notoriedad y resonancia en América Latina en los últimos treinta años. El planteo de nuevos y variados interrogantes vinculados al bienestar de las poblaciones ha jalonado, incluso, la definición de tres nuevas líneas de trabajo o estilos de abordar y narrar el pasado que Diego Armus ${ }^{1}$ ha identificado como "la nueva historia de la medicina, la historia de la salud pública y la historia sociocultural de la enfermedad". Los límites de cada uno es éstos subcampos son difusos, permeables y -por consiguiente- en sobradas oportunidades no es posible ubicar los análisis historiográficos de manera concluyente en sólo una de éstas categorías. Así, el presente estudio se halla inserto en los lindes de la nueva historia de la medicina y la nueva historia sociocultural de la enfermedad, puesto que intentamos colocar en diálogo tramas vinculadas al conocimiento biomédico y su circulación, tratamientos, procesos de profesionalización, medicalización, etc.

Particularmente, nos proponemos examinar los ritmos y rasgos de un mercado publicitario orientado a un público especializado. Indagaremos en las dinámicas del ofrecimiento de medicamentos y aparatología terapéutica en la revista publicada por la Asociación Médica Argentina entre 1914 y 1938, periodo delimitado por el estallido de la Gran Guerra y la culminación del período de entreguerra, respectivamente. Dichas dinámicas serán observadas a partir de la puesta en perspectiva de procesos político-económicos amplios que se hallaron

${ }^{1}$ Diego Armus. “¿Qué historia de la salud y la enfermedad?”. Salud Colectiva, Vol. VI, №1,2010, p.6. 
imbricados a las constantes mutaciones del concierto internacional, como el desarrollo industrial nacional en general, la puesta en marcha de la industria farmacéutica argentina, etc. Asimismo, en el plano local, atenderemos a variables ligadas al potencial público consumidor de la publicación; a saber: los médicos. Específicamente, consideraremos el proceso de profesionalización en el cual se encontraban inmersos, prestando especial atención a sus agendas de investigación, a sus vinculaciones con la ciencia internacional, variables que entendemos arrojarán luz sobre distintos estadios de consolidación de la élite galena. Convergentemente, incluiremos en nuestro estudio una aproximación a la trayectoria editorial de la revista en la cual se hallan insertas las publicidades, elemento insoslayable que también marcaría un derrotero particular del mercado bajo estudio.

Nuestro trabajo se inscribe en una corriente historiográfica renovada que rescata entramados vinculados a ciertas actividades de consumo. De acuerdo a lo planteado por Inés Pérez, en los últimos años se vislumbra un interés particular por la historia del consumo ${ }^{2}$ en América Latina, tendencia de la que Argentina no habría escapado. De hecho, recientes investigaciones han mostrado la relevancia del consumo para el análisis de distintas transformaciones sociales que exceden lo estrictamente económico, e involucran desde la reorganización de las identidades sociales, al mundo de la política y la vida cívica, pasando por las relaciones sociales y la intimidad ${ }^{3}$. En esta misma línea, partimos de considerar que el mercado publicitario de medicamentos e insumos médicos especializados deviene en una muestra que permite observar cómo los fenómenos locales, nacionales e internacionales referidos anteriormente se entraman de forma compleja y variante. Ahora bien, como señalase Susan Strasser, el consumo puede ser pensado como un prisma a través del que se puede ver distintos aspectos de la vida social ${ }^{4}$. Esto ha propiciado una relativa dispersión (tanto temática como disciplinar) de los estudios,

\footnotetext{
${ }^{2}$ Inés Pérez. "Apuntes para el estudio del consumo en clave histórica". Avances del Cesor, Vol. XII, N 13, 2015, p. 97.

${ }^{3}$ En este sentido, se destacan trabajos tales como: Andrea Lluch. Las manos visibles del mercado: intermediarios y consumidores en la Argentina (siglos XIX y XX). Rosario, Prohistoria, 2015; Natalia Milanesio. Cuando los trabajadores salieron de compras: nuevos consumidores, publicidad y cambio cultural durante el primer peronismo. Buenos Aires, Siglo XXI, 2014; Melina Piglia. Autos, rutas y turismo: el automóvil club argentino y el estado. Buenos Aires, Siglo XXI, 2014; Valeria Manzano. The Age of Youth in Argentina: Culture, Politics, and Sexuality from Perón to Videla. Chapel Hill, The University of North Carolina Press, 2014; Rebekah Pite. Creating a common table in twentieth-century Argentina: Doña Petrona, Women and Food. Chapel Hill, The University of North Carolina Press, 2013; Inés Pérez. El hogar tecnifcado: familias, género y vida cotidiana. Buenos Aires, Biblos, 2012; Eduardo Elena. Dignifying Argentina: Peronism, Citizenship, and Mass Consumption. Pittsburgh, University of Pittsburgh Press, 2011; Sandra Fernandez. La revista EL Círculo o el arte de papel. Una experiencia editorial en la Argentina del Centenario. Murcia, Universidad de Murcia, 2010; Isabella Cosse. Mafalda: historia social y política. Buenos Aires, Fondo de Cultura Económica, 2010; Paula Caldo. Mujeres cocineras. Hacia una historia sociocultural de la cocina, Argentina a fines del

siglo XIX y primera mitad del XX. Rosario, Prohistoria, 2009; Fernando Remedi. Dime qué comes y cómo lo comes y te diré quién eres. Una historia social del consumo alimentario en la modernización argentina. Córdoba, 1870- 1930. Córdoba, Centro de Estudios Históricos "Prof. Carlos S. A. Segreti", 2006.

${ }^{4}$ Susan Strasser. "Making consumption conspicuous: transgressive topics go mainstream". Tecnology and Culture, Vol. V, $\mathrm{N}^{\circ} 43,2002$, p.756.
} 


\section{Dinámicas publicitarias en Argentina: una aproximación al caso de la Revista de la Asociación Médica Argentina (1914-1938)}

que en sobradas oportunidades hacen foco en discusiones que contribuyen a otros campos, revisando algunos aspectos de la historia del consumo, pero sin centrarse en él. Lo cierto es que, a pesar del desarrollo que hemos marcado previamente, las investigaciones sobre la historia del consumo aún son escasas y no existe un campo específico de estudios identificados estrictamente con este concepto. De hecho, si esta vertiente analítica comenzó a ganar fuerza en Estados Unidos y Europa en los años ochenta, el interés sobre estos temas sólo comenzó a cristalizarse en nuestras latitudes nacionales hacia fines de los noventa de la mano de los aportes de Fernando Rocchi ${ }^{5}$.

En esta agenda notoriamente variada y difusa, el análisis de tendencias o comportamientos de consumo imbricados a fenómenos de salud y enfermedad resulta particularmente exiguo. Claro que aunque las vinculaciones históricas entre las publicidades y el mercado de los productos especializados en salud constituyen problemáticas de escaso estudio por parte de la historiografía argentina, debemos remarcar que un conjunto de trabajos ha tenido el mérito de plantear valiosos interrogantes y abordar fuentes históricas imbricadas a estos entramados. Estas investigaciones se han desarrollado a partir de dos líneas de trabajo. Una de ellas, representada por los estudios de Armus ${ }^{6}$, Carbonetti y Rodríguez ${ }^{7}$, Carbonetti ${ }^{8}$, Múgica ${ }^{9}$, Biernat y Simonetto ${ }^{10}$, los cuales ponen en perspectiva aristas significativas del ofrecimiento de productos medicinales en periódicos y revistas de difusión hacia

\footnotetext{
5 Para mayor información, véase: Fernando Rocchi. "Consumir es un placer: la industria y la expansión de la demanda en Buenos Aires a la vuelta del siglo pasado". Desarrollo Económico, Vol. V, № 148, 1998, pp. 533-558; Fernando Rocchi. "Inventando la soberanía del consumidor: publicidad, privacidad y revolución del mercado en la Argentina (1860-1940)”, en Fernando Devoto y Marta Madero (compiladores) Historia de la vida privada en la Argentina. Buenos Aires, Taurus, 1999, pp. 201-322; Fernando Rocchi. "La americanización del consumo: las batallas por el mercado argentino, 1920-1945”, en María I. Barbero y Andrés M. Regalsky (editores) Estados Unidos y América Latina en el siglo XX. Transferencias económicas, tecnológicas y culturales. Buenos Aires, UNTREF, 2003, pp. 131-189; Fernando Rocchi. Chimneys in the Desert. Industrialization in Argentina during the Export Boom Years, 1870-1930, Stanford University Press, 2006; Fernando Rocchi. "La sociedad de consumo en tiempos difíciles: el modelo estadounidense y la modernización de la publicidad argentina frente a la crisis de 1930". Historia Crítica, № 65, 2017.

6 Diego Armus. La Ciudad Impura. Salud, Tuberculosis y Cultura en Buenos Aires, 1870-1950. Buenos Aires, Edhasa, 2007; Diego Armus. "Medicina casera, remedios y curanderos en los inicios de la medicalización de la ciudad moderna. Buenos Aires, 1870-1940”. Tempos Históricos, XX,2016, pp. 4780.

${ }^{7}$ Adrián Carbonetti y María Laura Rodríguez. "Las epidemias de cólera en Córdoba a través del periodismo: la oferta de productos preservativos y curativos durante la epidemia de 1867-1868". Hist. cienc. saude-Manguinhos, Vol. XIV, N² 2, 2007, pp. 405-419.

${ }^{8}$ Adrián Carbonetti. "Ofrecimiento de productos en épocas de epidemia. La publicidad en momentos de la pandemia de "gripe española" en Argentina, 1918 - 1919", en Miguel Ángel Cuenya y Rosalina Estrada Urroz, (compiladores), Nuevas miradas desde América Latina y México. Enfermedad y control social. Siglos XIX y XX. México, Instituto de Ciencias Sociales y Humanidades de la benemérita Universidad Autónoma de Puebla, 2013, pp. 147-167.

${ }^{9}$ María Luisa Múgica. “'Males vergonzantes' y prostitución reglamentada. Rosario, Argentina (18741932)”. Asclepio. Revista de Historia de la Medicina y de la Ciencia, Vol. LXVIII, N², 2016, pp. 1-18.

${ }^{10}$ Carolina Biernat y Patricio Simonetto. "Provisión pública y oferta privada de medicamentos contra las enfermedades venéreas. Argentina 1930-1945”. Revista Ciencias de la Salud, Vol. XV, N ², 2017, pp. 273-291.
} 


\section{María Dolores Rivero}

fines del siglo XIX y la primera mitad del XX en Argentina. No obstante, dichos trabajos restringen su interés a abordar aspectos socioculturales vinculados al desarrollo de enfermedades concretas. Entendemos que el análisis de las relaciones entre las enfermedades y los fenómenos de comercialización de medicamentos constituye una puerta de ingreso privilegiada al estudio de las publicidades y el mercado de la salud. Sin embargo, desde nuestra visión, el recorte en torno a las dolencias tiende a reducir el foco de estudio a una situación de crisis social y epidemiológica, ya que ésta última ocupa el centro de la escena analítica.

Por otro lado, recientemente se ha desarrollado una segunda línea de trabajo más ligada a nuestras actuales inquietudes- sugerida por Rodríguez y Carbonetti, Rizzi y Rivero ${ }^{11}$-quienes plantean que las publicidades farmacéuticas y de insumos médicos especializados pueden instituirse como elementos analíticos clave para abordar procesos históricos más complejos, por ejemplo aquellos ligados a la consolidación del mercado farmacéutico y el de productos de uso médico orientados a un público profesional. En nuestra propuesta, partimos de ese supuesto, procurando mostrar -a partir de un caso concreto- que las publicidades constituyen referencias empíricas privilegiadas, a partir de las cuales es posible abordar el proceso de construcción de un mercado de oferta especializada.

Anclado en un abordaje de carácter cualitativo, nuestro aporte se define entonces por rescatar y profundizar el valor heurístico y hermenéutico de las publicidades. Trabajar con estos avisos y su soporte -la revista- nos permite poner en perspectiva una fuente altamente significativa, cuyo objetivo fundacional fue "centralizar las fuerzas intelectuales consagradas al estudio de la medicina y fortalecer el espíritu del cuerpo, estrechando los lazos de unión entre los miembros de una misma familia"12. En consonancia con este propósito, la referida publicación se erigió-desde las postrimerías del siglo XIX- como un factor esencial en la construcción de un espacio de divulgación y socialización entre los médicos y la ciencia médica de la Argentina.

\section{4-1918: los primeros pasos de un mercado especializado}

Desde fines del siglo XIX, la Argentina se integró en el sistema de División Internacional del Trabajo -cuyo centro era Inglaterra- como productor agropecuario e importador de productos manufacturados ${ }^{13}$. Es a partir de este momento que podemos hablar de una etapa agroexportadora o de producción de bienes primarios exportables, caracterizada por un alto grado de integración de la economía

\footnotetext{
${ }^{11}$ María Laura Rodríguez; Adrián Carbonetti; Gastón Rizzi y Dolores Rivero. "El mercado de las publicidades de medicamentos e insumos médicos especializados en el interior de Argentina: el caso de la «revista del Círculo Médico de Córdoba» y la «Revista Médica de Córdoba», Argentina, 19121938". Asclepio. Revista de Historia de la Medicina y de la Ciencia, Vol. LXVI, Nㅜ 2, 2016, pp. 1-16.

${ }^{12}$ Revista de la Sociedad Médica Argentina, Buenos Aires, -/2/1892, p. 4

${ }^{13}$ Pablo Gerchunoff y Lucas Llach. El ciclo de la ilusión y el desencanto. Un siglo de políticas económicas argentinas. Argentina, Ariel, 2010, p.18.
} 


\section{Dinámicas publicitarias en Argentina: una aproximación al caso de la Revista de la Asociación Médica Argentina (1914-1938)}

argentina al mercado mundial, que traía aparejada una frontera muy débil frente al sistema internacional de dominación económica ${ }^{14}$. Ahora bien, la incorporación del país al sistema mundial que se estructuraba, como productor de materias primas alimenticias, se vio favorecida porque la región litoral- la más apta para ello- no era una "zona vacía" y ya venía históricamente orientando su producción hacia la actividad agropecuaria. No obstante, pese a las características territoriales y productivas que beneficiaron la inserción del país al sistema internacional, también fueron necesarios ciertos aportes extranjeros: contingentes de inmigrantes y gran cantidad de capitales, direccionados fundamentalmente hacia la región pampeana ${ }^{15}$, cuya extensión territorial se amplió. Ello determinó que los desequilibrios existentes entre Interior y Litoral se acentuaran ${ }^{16}$.

Ahora bien, en el marco de este sistema económico nacional focalizado en la producción de bienes primarios exportables, no debemos soslayar la importancia del desarrollo industrial. En la lectura de dicho proceso, nos encontramos con diferentes posicionamientos; por un lado, desde la perspectiva de Rofman y Romero ${ }^{17}$, el gobierno radical imperante por aquellos años no se propuso nunca (ni en la práctica política, ni siquiera en su programa) modificar los parámetros fundamentales de la Argentina agroexportadora. Su acción de gobierno respetó los intereses agropecuarios; no se modificó el latifundio ni se debilitó el poder de los frigoríficos; tampoco hubo tipo alguno de política de promoción industrial, pese a que la Guerra Mundial (1914-1918) creó condiciones reales objetivas, que según esta lectura, fueron desaprovechadas.

Por su parte, Gerchunoff y Llach, sostienen que la expansión industrial previa a 1914 no fue menor; las manufacturas cuya producción creció más fuerte fueron las que dependían del tipo de desarrollo agroexportador de la época (como los alimentos y las bebidas) ${ }^{18}$. Comparado con la situación de 1880, entonces, el estado de la industria próximo a la Primera Guerra Mundial era mucho más avanzado de lo que tradicionalmente suele considerar la historiografía especializada. De hecho, el producto industrial se multiplicó aún más rápidamente que la producción global, aunque -cabe resaltar- partía de bases mínimas.

El motor principal de esa expansión fue el crecimiento del mercado interno (las exportaciones industriales eran insignificantes), algo que ha sido frecuentemente olvidado y resalta el carácter complementario, más que rival, entre la industria y el sector rural en este periodo. La industria no solo aprovechaba, sino que también ayudaba a consolidar un verdadero mercado nacional en el que se imponían cada vez más las prácticas habituales del capitalismo moderno (economías de escala,

\footnotetext{
14 Alejandro Rofman y José Luis Romero. Sistema socioeconómico y estructura regional en la Argentina. Buenos Aires, Amorrortu, 1997, p.113.

15 En la ciudad de Buenos Aires, el 51\% de la población total era extranjero, con claro predominio de italianos y españoles.

${ }^{16}$ Alejandro Rofman y José Luis Romero. Sistema socioeconómico..., Op. Cit, p.115.

17 Ídem, p. 128.

18 Pablo Gerchunoff y Lucas Llach. El ciclo de la ilusión..., Op. Cit, pp. 37-38.
} 
incorporación de tecnologías, propaganda, etc). Sin embargo y, a pesar de lo sostenido hasta el momento, por estos años no es posible hablar de un genuino "despegue" industrial. Más bien, podemos decir que la industria argentina estaba dando sus primeros pasos, y esta dinámica colaboraría en definir el contexto de desarrollo de lo que consideramos una etapa inicial del mercado publicitario de medicamentos e insumos médicos.

En lo concerniente a la industria farmacéutica argentina, tal y como señalan Campins y Pfeiffer ${ }^{19}$, su derrotero se encontró signado por la actividad agropecuaria previamente reseñada. A la dotación inicial de factores naturales -que posibilitaron la producción de medicamentos biológicos- se sumaron las mejoras tecnológicas, la disponibilidad de recursos humanos cualificados y una exigente demanda interna que acompañó al acelerado crecimiento económico del país. A esto se agregó un marco regulatorio liberal que favorecía las inversiones privadas en esta rama industrial ${ }^{20}$.

En este contexto, la ciudad de Buenos Aires -centro de poder histórico, cuyo predominio sobre el resto del país cristalizaría con la constitución definitiva de la capital de la República en 1880- bien puede tomarse como un caso excepcional desde donde visualizar cómo las transformaciones económicas nacionales -propias de los años en estudio- pueden servir de contexto explicativo para el análisis de la conformación del mercado publicitario bajo estudio. Además de instituirse como el enclave receptor de una gran masa de inmigrantes, escenario privilegiado para la emergencia de los sectores medios y de una espectacular y rápida urbanización, punto decisivo del despegue de la zona litoral del país ${ }^{21}$, la capital nacional fue testigo del surgimiento y desarrollo de la ciencia médica argentina. Se fundarían aquí, durante el siglo XIX, la Academia de Medicina, la Asociación Médica Bonaerense, el Círculo Médico Argentino y la Asociación Médica Argentina, entre otras. Del seno de esta última -creada en 1891- nacería poco tiempo después la "Revista de la Sociedad Médica Argentina", ante una inminente necesidad de divulgar y discutir los saberes que circulaban en el campo médico por aquellos años. En el marco de sus metas fundacionales, la editorial expresaba:

\footnotetext{
${ }^{19}$ Monica Campins y Ana Pfeiffer. "La importancia de las redes sociales en los orígenes de la industria farmacéutica argentina. El caso de los catalanes en Argentina". Revista de Historia Industrial, Nro. 47,2011, pp. 27-28.

${ }^{20} \mathrm{El}$ conjunto de regulaciones con que contaba el arte de esta industria en Argentina se expresaba por medio de tres instrumentos: la ley de Patentes de invención no 111 de 1864, el código oficial o Farmacopea Argentina editado por primera vez en 1870 y la ley de farmacia n.o 4.687 de 1905. La ley de patentes prohibía expresamente el patentamiento de los productos farmacéuticos y de los procesos necesarios para su obtención, considerados bien de la humanidad. La falta de una ley de patentes promovió el desarrollo de copias o duplicaciones entre las empresas locales. En cuanto a la Farmacopea Argentina, este código establecía las características de las drogas, las formas farmacéuticas, los medicamentos y las técnicas analíticas para la comprobación de la calidad del producto final. Este código era el único control de calidad que realizaba por su cuenta cada una de las empresas locales. Por último, la ley 4.687 de 1905 establecía una regulación corporativa que excluía de la elaboración y expendio de medicamentos a todo aquel que no fuera farmacéutico diplomado en una Universidad Nacional (Campins y Pfeiffer, 2011: 28-29).

${ }^{21}$ Hernán Otero. Estadística y Nación. Una historia conceptual del pensamiento censal de la Argentina moderna. 1869-1914. Buenos Aires, Prometeo, 2006, p. 167.
} 


\title{
Dinámicas publicitarias en Argentina: una aproximación al caso de la Revista de la Asociación Médica Argentina (1914-1938)
}

\begin{abstract}
Nuestros propósitos son modestos, pero prácticos; haremos todo lo posible por no ocupar nuestras páginas sino con materiales de observación original, dando siempre un lugar secundario a los trabajos estrangeros [sic], siempre que no sean remitidos especialmente por alguno de nuestros miembros corresponsales. Para colaborar en ella no es menester ser socio de nuestra corporación y desde hoy queda a la disposición de todo el que quiera contribuir con su grano de arena al progreso de las ciencias médicas ${ }^{22}$.
\end{abstract}

La primacía que esta revista pretendía otorgarle a los trabajos de corte nacional da cuenta de la marcada necesidad de los médicos de Buenos Aires de congregarse y estimularse en el marco de su profesión, como así también de contribuir cada uno en su esfera al "progreso" de la ciencia que se estaba cultivando. En este sentido, y ponderando su gran alcance, sostenemos que la publicación emanada desde el seno de esta sociedad, terminaría por instituirse como un espacio editorial privilegiado para la colocación de avisos publicitarios dirigidos a los galenos de todo el país.

Para los inicios de nuestro periodo de análisis, la revista de la Sociedad anuncia que:

...ha conquistado el puesto de honor entre las publicaciones médicas del país, constituyendo el exponente más elevado de nuestra cultura médica. Y nos es grato considerar con orgullo que ha traspasado los límites de nuestro país para ser apreciada dignamente fuera de él23.

En efecto, tras veinte años de que se emitiera su primer ejemplar, la referida editorial ya contaría con una trayectoria que la colocaría por fuera de nuestras latitudes nacionales, como así también a los galenos que publicaban sus respectivos trabajos en ella.

Asimismo, y en consonancia con la idea de visibilizar la producción científica nacional, en 1912 se explicita que, con el propósito de completar la revista, la redacción baraja la posibilidad (que luego se vería materializada) de incluir secciones nuevas, entre las cuales se encontraría un "Archivo de observaciones" y otra de "Bibliografía nacional". Dentro de esta última se incluirían las tesis de las facultades de medicina de la Argentina, como así también secciones específicas que albergarían trabajos pertenecientes a diferentes ramas de la medicina (clínica médica, quirúrgica, pediatría, obstetricia, higiene, terapéutica, otorrinolaringología, oftalmología, odontología, sifilografía, etc). Esta tendencia a mostrar de manera particular y por separado los artículos de las especialidades sería una constante en la revista durante nuestro primer período bajo estudio. Es que "frente al avance del conocimiento científico fueron surgiendo diversas Sociedades con sus correspondientes medios de difusión: en Julio de 1908 la Sociedad de Obstetricia y

22 Revista de la Sociedad Médica Argentina..., Op. Cit.,p. 6.
23 Revista de la Sociedad Médica Argentina, Buenos Aires, -/3-4/1912, p.105. 


\section{María Dolores Rivero}

Ginecología, en 1911 la Sociedad de Pediatría y en 1917 la de Radio y Electrología"24 y la Revista de la Sociedad Médica Argentina se haría eco de estas apariciones.

Ahora bien, en lo relativo al mercado publicitario que pretendemos abordar, debemos destacar que durante el periodo que va desde 1912 a 1918, la publicación tendría entre sus directivos a destacadas personalidades del ámbito médicoacadémico nacional. En 1915, año en que cambiaría el nombre de "Revista de la Sociedad Médica Argentina" a "Revista de la Asociación Médica Argentina", era nada menos que Bernardo Houssay -premio Nobel de Fisiología y Medicina y creador de la escuela de fisiología más importante de América Latina ${ }^{25}$ - quien estaba a su cargo, marcando un derrotero particularmente cientificista en las páginas de la editorial. Así, hasta 1917 -momento en que comienzan a registrarse dinámicas muy notables de colocación de avisos- la revista tendrá un perfil netamente académico. Como venimos reseñando, se observará una búsqueda incesante por la puesta en perspectiva de la producción médica argentina, y ya hacia finales de esta primera etapa planteada -con el Dr. Carlos Bonorino Uadondo a la cabeza, primero, y luego con Carlos Alberto Castaño- ciertos elementos darían cuenta de la importancia que irían adquiriendo las vinculaciones con la ciencia internacional para la sociedad médica que daba vida a la publicación. Así, tras el primer Congreso Nacional de Medicina que se realizó en septiembre de 1916 en la Capital Federal, se nombraba a “...Aloysio de Castro y Carlos Chagas socios honorarios de la Asociación por su respetada labor"; el primero, como Decano de la Facultad de Medicina de Rio de Janeiro y delegado del Instituto Oswaldo Cruz, el segundo ${ }^{26}$. En la mayor parte de los años signados por las vicisitudes propias de un escenario mundial bélico, entonces, la revista de la Asociación Médica Argentina no se erigiría como objeto de una colocación sistemática de publicidades de medicamentos e insumos médicos especializados; sería recién hacia el final del periodo que las dinámicas publicitarias comenzaría a adquirir notoriedad. A partir de ese momento, se observa una profusa oferta, registrándose un total de dieciséis avisos. Dentro de esa cantidad, una particularidad que presenta el caso de la revista porteña es que ya en una etapa inicial se colocan avisos de específicos nacionales (diez en total), mientras los extranjeros son escasos (sólo se registran cuatro); los restantes no especifican los países productores. Esto nos induce a conjeturar, por un lado, que la revista de la Asociación Médica Argentina ya constituía un nicho de interés para las iniciativas comercializadoras foráneas. Por otro, nos estaría indicando que los productores nacionales de medicamentos apelaban a la colocación de sus publicidades en una revista médica que tendría un cierto grado de alcance. En este sentido, resulta necesario revisar algunos datos relativos al derrotero editorial de estos años; tan sólo durante 1916 se publicaron sesenta artículos en la revista (siendo ochenta y

\footnotetext{
${ }^{24}$ Armando Guglielminetti. "Jornadas Homenaje al $120^{\circ}$ Aniversario de la Revista de la Asociación Médica Argentina”. Revista de la Asociación Médica Argentina, Vol. CXXVI, N³, 2013, p. 7

25 Juan César García. "Historia de las instituciones de investigación en salud en América Latina: 18801930”. Educación médica y salud, Vol XV, N¹1, 1981, p. 75

26 Revista de la Asociación Médica Argentina, Buenos Aires, -/5/ 1917, p. 48.
} 


\section{Dinámicas publicitarias en Argentina: una aproximación al caso de la Revista de la Asociación Médica Argentina (1914-1938)}

dos los autores nacionales y tres extranjeros) y ochenta y seis resúmenes del Primer Congreso Nacional de Medicina. El total de socios hasta el 31 de Marzo de 1917 fue nada menos que quinientos treinta y dos. Asimismo, se informaba que la aparición de la publicación era cada dos meses, pero se estarían desarrollando grandes esfuerzos para que se torne mensual ${ }^{27}$. En otros términos, nos encontramos frente a un espacio de divulgación científica que contaría con una impronta y trascendencia insoslayables ${ }^{28}$.

En lo relativo específicamente al campo medicamentoso, otra singularidad que presenta este mercado se liga al origen de los productos. En efecto, conforme con la primacía del modelo económico agroexportador, las publicidades analizadas dan cuenta de que la industria farmacéutica argentina se encontraba cimentada en los productos del suelo, es decir, biológicos. Así, se observa en las fotografías 1, 2 y 3 una primacía de publicidades de sueros, vacunas y fermentos de origen nacional. No obstante, no debemos soslayar que por estos años no podemos hacer referencia a un marcado ascenso de la industria nacional; pese a las matrices socio-económicas que definió la Gran Guerra, en Argentina no hubo un genuino proceso de sustitución de importaciones de medicamentos e insumos médicos especializados. De hecho, las ofertas relativas a éstos últimos materiales, cuya elaboración dependía de procesos tecnológicos que implicaban cierto grado de complejidad, eran de origen internacional como puede observarse en las fotografías 4 y 5.

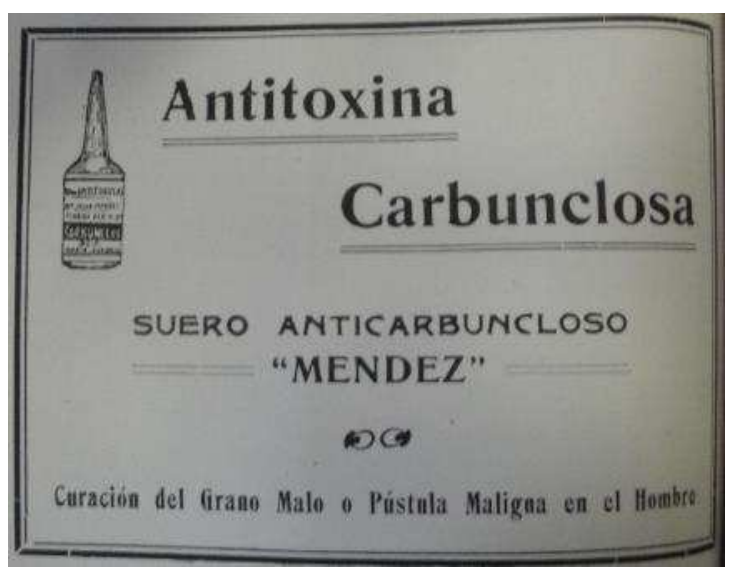

Fotografía 1: Antitoxina Carbunclosa. Revista de la Asociación Médica Argentina.

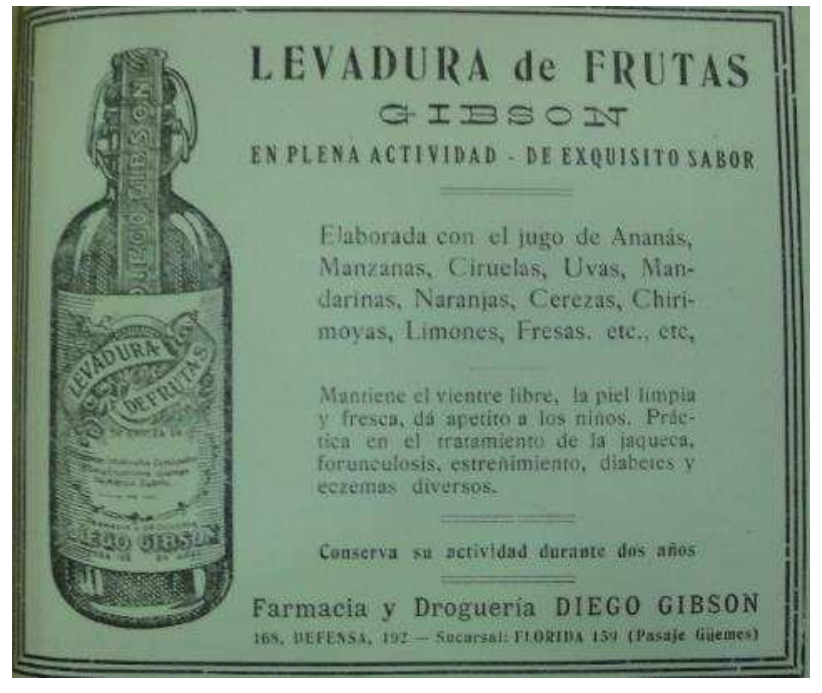
Suplemento de especialidades, 1917, p. 108.

Fotografía 2: Levadura de frutas. Gibson. Revista de la Asociación

\footnotetext{
27 Revista de la Asociación Médica Argentina, Buenos Aires, -/5/1917, s/p.

28 Entre su importante número de redactores, para 1917, hallamos personalidades como Ignacio Allende, Gregorio Aráoz Alfaro, Mariano Castex, Carlos Bonorino Udaondo, Daniel J. Cranwell y Miguel Ángel Roffo.
} 
Médica Argentina. Suplemento de especialidades, 1917, p. 131.

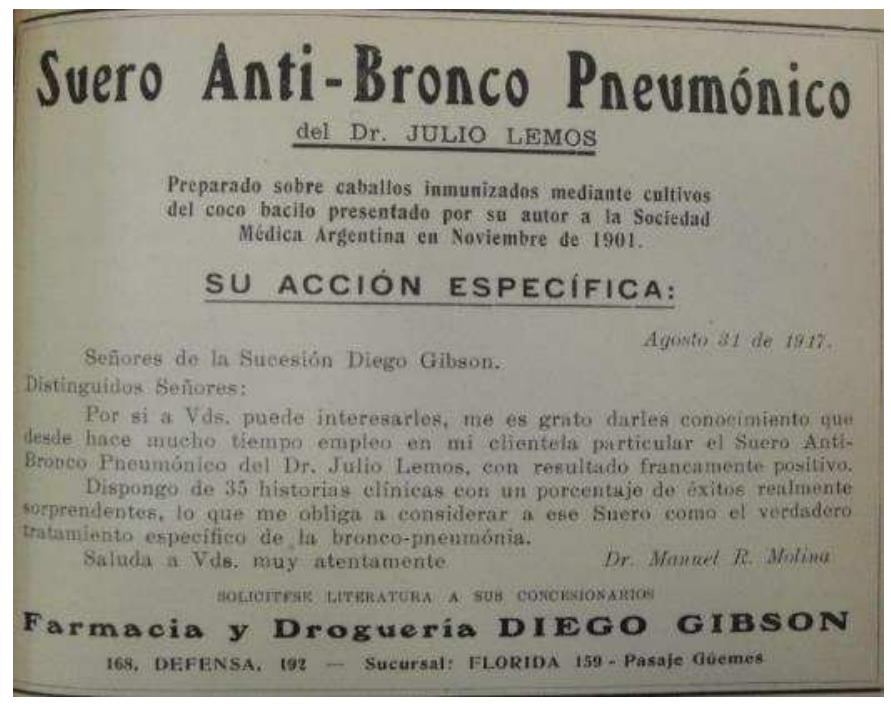

Fotografía 3: suero anti-bronco pneumónico.

Revista de la Asociación Médica Argentina ,1918, p.125 
Dinámicas publicitarias en Argentina: una aproximación al caso de la Revista de la Asociación Médica Argentina (1914-1938)

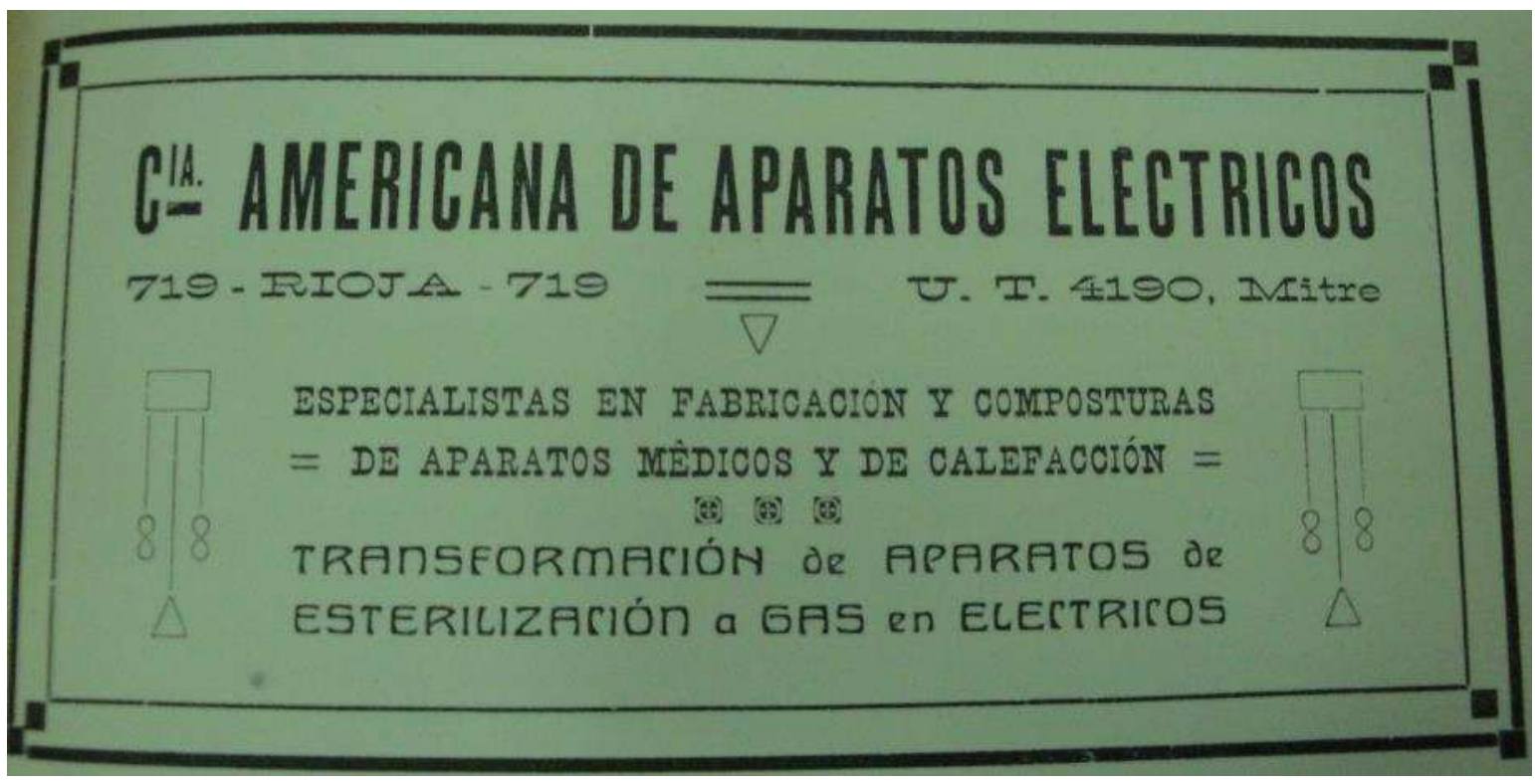

Fotografía 4: Cia Americana de aparatos eléctricos. Revista de la Asociación Médica Argentina. Suplemento especialidades, 1917, p. 94.

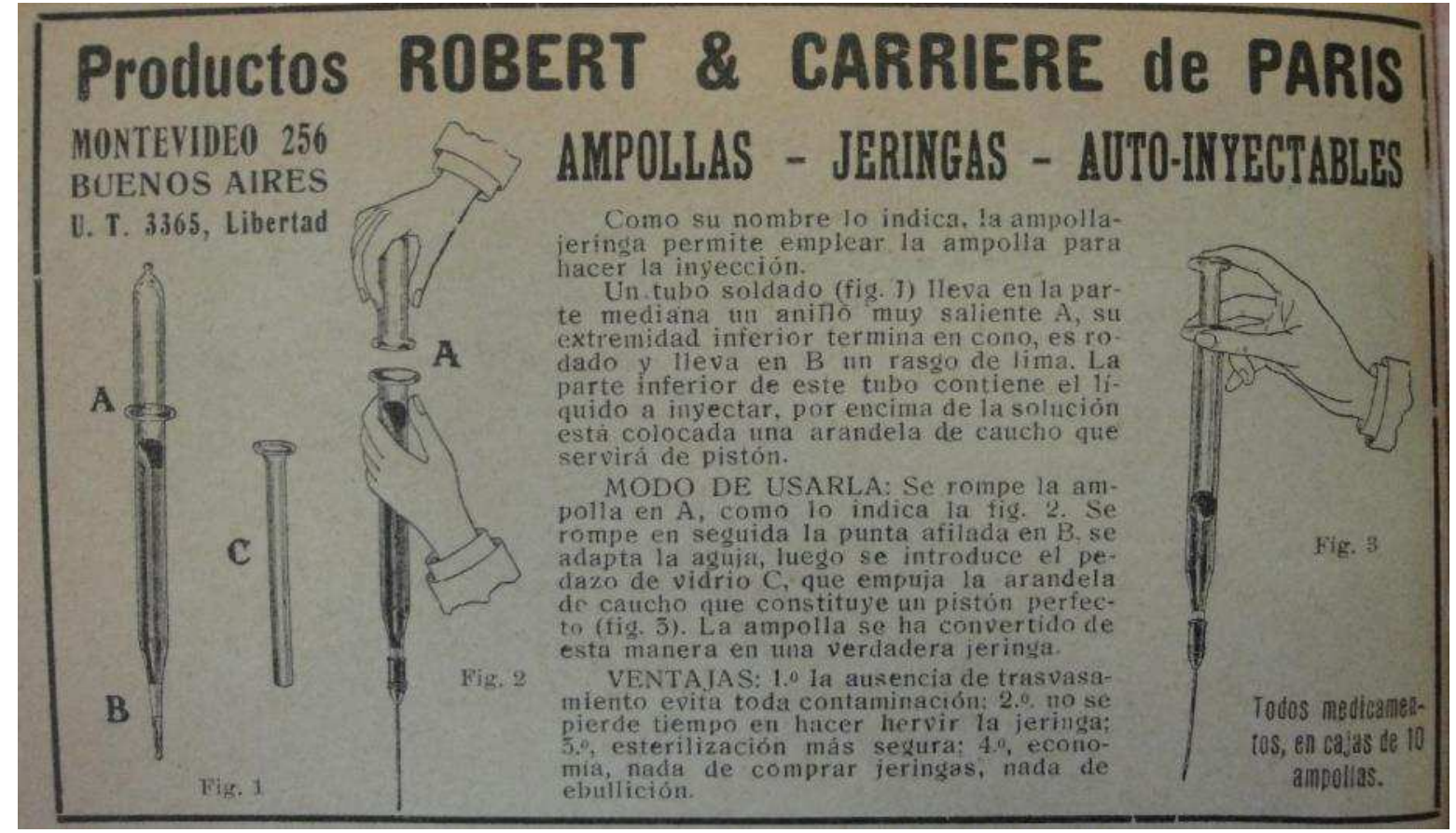

Fotografía 5: Ampollas- Jeringas- Autoinyectables. Revista de la Asociación Médica Argentina, 1917, XXVI. N 151. Junio, p. 594.

En cuanto a las afecciones que los medicamentos y tratamientos ofertados estaban destinados a curar, es posible observar una exigua especificidad; en términos cuantitativos, hemos hallado siete anuncios que podrían ubicarse dentro de un conjunto donde prevalecen remedios destinados a curar múltiples y variadas 


\section{María Dolores Rivero}

enfermedades. Así, nos encontramos con baños termales "especiales para parálisis, reumatismos agudos, enfermedades nerviosas y de la piel, gota y muchas otras"29, con el Haptinógeno NEUMO Méndez, destinado a "septicemias en general" neumonías, influenza, otitis, infecciones oculares ${ }^{30}$, etc-; la misma tendencia se observa en el caso del Fermento láctico vivo, "cultivo puro de células jóvenes ... aptas para actuar como remedio desde el momento mismo de su ingestión por el enfermo" 31 y a levadura de frutas Gibson, "práctica en el tratamiento de la jaqueca, forunculosos, estreñimiento, diabetes y eczemas diversos"32. En este sentido, cabe recordar -por un lado- que en este momento se asiste a una etapa epidemiológica pretransicional (propia del siglo XIX y principios del XX); una estructura por edad relativamente joven de la población estaba afectada por la incidencia de enfermedades infecciosas y parasitarias en general, predominantemente entre los niños y jóvenes. Mientras en las edades mayores este tipo de dolencias sólo representaba el $20 \%$ de las causas de muerte, entre los menores de 20 años alcanzaba al 36\% del total ${ }^{33}$. El desarrollo de estas afecciones se vio favorecido por un contexto socio- demográfico particular: el aluvión inmigratorio al que referimos previamente generó un fuerte crecimiento poblacional, entendido en términos de revolución demográfica, hecho que trajo aparejado consigo la aparición de serios problemas sanitarios debidos al hacinamiento, la falta de higiene ambiental y de los alimentos, sobre todo en las urbes. De esta manera se generaron cadenas epidemiológicas que prepararon un campo de cultivo para el desarrollo de dolencias de carácter infecto-contagiosas endémicas y epidémicas, como la tuberculosis y la viruela o el sarampión ${ }^{34}$.

Por otra parte, tal y como señala Ricardo González Leandri35, en estos primeros años del siglo XX los profesionales de la salud -específicamente los médicos- aún estaban luchando por obtener el monopolio cognitivo del arte de curar; comenzaban a acelerarse las búsquedas de conformación de la medicina académica como saber hegemónico que habían empezado a entreverse en nuestro país a mediados del siglo XIX. Particularmente, y en términos numéricos, el censo nacional de 1914 arroja un total de sólo 3.455 médicos en todo el territorio nacional, mientras 1.765 de ellos se encontraban en la Capital. En este escenario, las especialidades y ramas específicas de la biomedicina no se hallaban acentuadamente delimitadas. Ahora bien, es interesante remarcar que en este

${ }^{29}$ Revista de la Asociación Médica Argentina, Buenos Aires, -/6/1917, p. 1204.

${ }^{30}$ Revista de la Asociación Médica Argentina, Suplemento Especialidades, Buenos Aires -/-/ 1917,p. 74

${ }^{31}$ Revista de la Asociación Médica Argentina, Suplemento Especialidades, Buenos Aires, -/-/ 1918, p. 3.

32 Revista de la Asociación Médica Argentina. Suplemento de especialidades, Buenos Aires, -/-/ 1917, p. 131.

${ }^{33}$ Bailey Lincoln. Morbilidad y mortalidad en la edad preescolar. Buenos Aires, Aniceto López, 1934.

34 Adrián Carbonetti y Dora Celton. "La transición epidemiológica", en Susana Torrado, (compiladora), Población y bienestar en la Argentina del primero al segundo centenario. Una historia social del siglo XX. Buenos aires, EDHASA, 2007, p.371.

35 Ricardo González Leandri. "Asociacionismo y representación de intereses médicos en Buenos Aires, 1852-1880". Asclepio. Revista de Historia de la Medicina y de la Ciencia, Vol. L, N² 2, 1998, pp. 187-203. 


\section{Dinámicas publicitarias en Argentina: una aproximación al caso de la Revista de la Asociación Médica Argentina (1914-1938)}

contexto de escasa especialización, el mercado publicitario analizado arroja datos acerca de un subcampo de la medicina que ya estaría dando sus primeros pasos como tal; la ginecología. Como podemos observar en las fotografías 6 y 7, la oferta publicitaria orientada a trastornos particularmente "femeninos" sí era definida e individualizaba notoriamente las afecciones sobre las cuales actuaba el producto en cuestión.

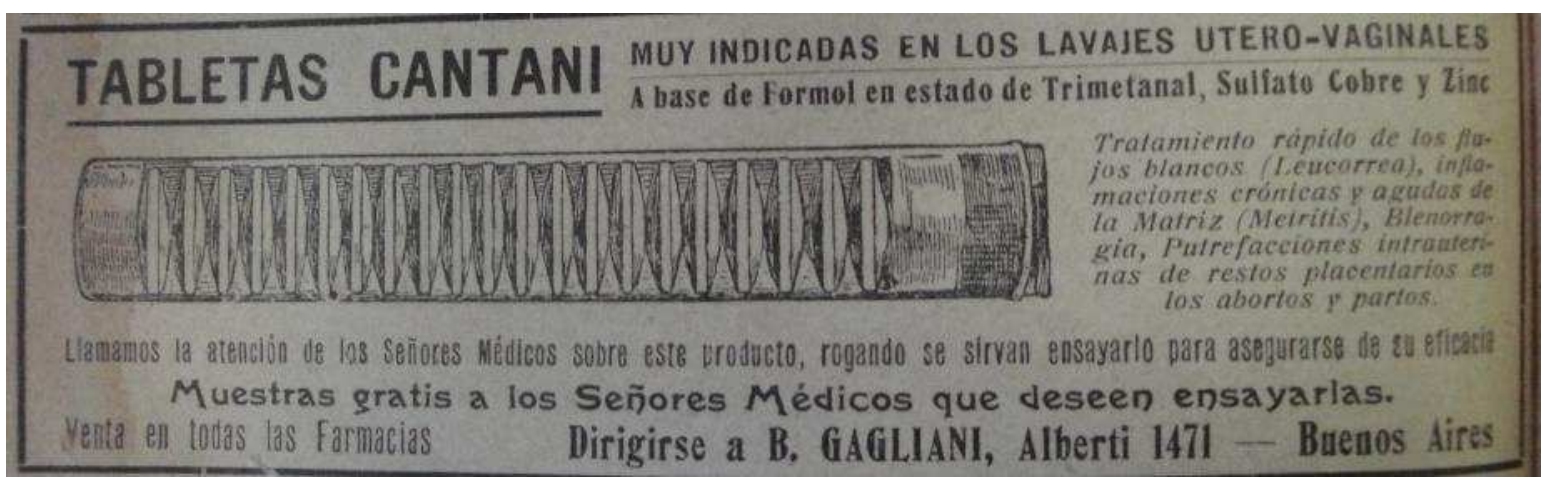

Fotografía 6: Tabletas Catani. Revista de la Asociación Médica Argentina, 1917, XXVI. N 151. Junio, p. 594.

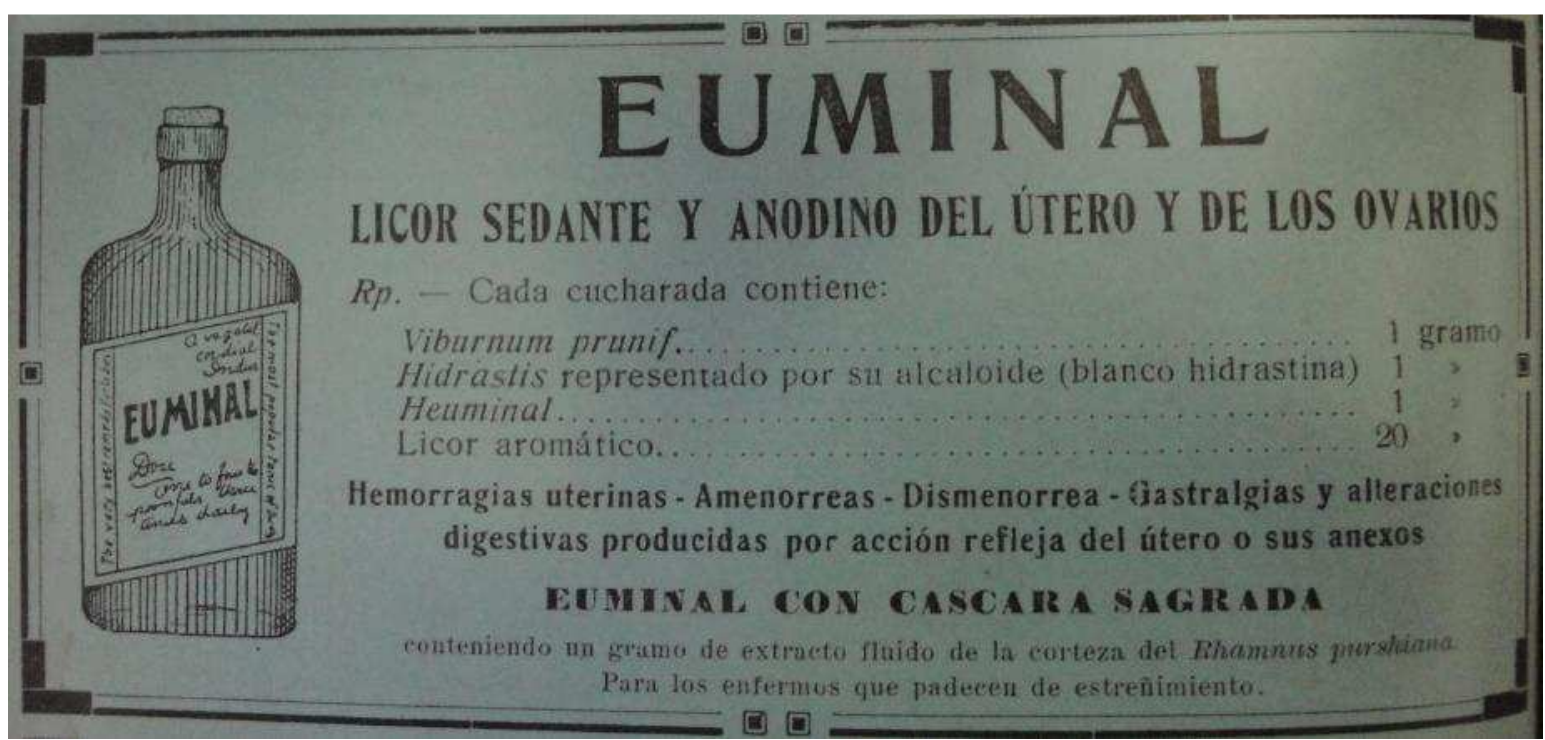

Fotografía 7: Euminal. Revista de la Asociación Médica Argentina, 1917, XXVII. № $156, \mathrm{~s} / \mathrm{p}$.

En un nivel discursivo, debemos subrayar el marcado interés de las empresas comercializadoras por acercarse de manera directa al potencial público consumidor de la revista. De acuerdo a lo observado en las publicidades bajo estudio, la mayor parte de los productos ofertados no parecían contar aún con el reconocimiento ni con la suficiente credibilidad en el ámbito médico, motivo por el cual resultaba indispensable apelar a estrategias tales como la que aparece en la fotografía 3. En este caso, quien asegura que el producto da resultados ampliamente positivos es, precisamente, un galeno. Él mismo aseguraba tener en su poder una gran cantidad 


\section{María Dolores Rivero}

de historias clínicas que avalaban el éxito del mencionado tratamiento. De manera convergente, y en pos de aumentar la clientela, el aviso invitaba al lector a "solicitar la literatura a sus concesionarios"36. Una estrategia similar a esta última puede observarse en la fotografía 6, donde se ofrecían "muestras gratis a los señores médicos..."37. Estos enunciados podrían estar relacionados con el grado incipiente de desarrollo de industria farmacéutica local; gran parte de los productos nacionales correspondientes a esta rama aún no se hallaba entre las filas de los más prescritos.

Otro rasgo presente en los anuncios examinados lo constituyen las composiciones químicas de los productos y sus formas de suministro, como es posible observar en las fotografías 5, 6 y 7. Se trataba, fundamentalmente, de explicitar -a partir de un lenguaje técnico y específico- la información más relevante para el universo que podía recetar los medicamentos en cuestión a los pacientes, o utilizar -en el marco del ejercicio de su profesión- los insumos tecnológicos. Sin embargo, no en todos los casos observamos los mismos entramados discursivos. De hecho, determinados anuncios nos han llevado a conjeturar marcados desplazamientos. Es que en esta primera etapa también identificamos la colocación de avisos que destacan elementos escasa o nulamente relevantes para los galenos pero sí para el público general; a saber: el sabor del producto (como en el caso de la Levadura de frutas dispensada por la farmacia y droguería Diego Gibson), la comodidad y liviandad de la faja elástica Gesell ${ }^{38}$, etc.

Las dinámicas colocadas en perspectiva nos conducen a proponer -durante los años de la Primera Guerra Mundial- la existencia de un momento inicial en el mercado publicitario examinado. Si bien la editorial en la cual se colocaban los anuncios existía desde fines del siglo XIX, aún en la primera década del XX no se constituía como un espacio por excelencia para publicitar medicamentos o insumos médicos especializados. Tal vez, esta orientación se encontrara signada por un perfil notoriamente cientificista de la revista, en cuyo directorio se encontraban destacadas personalidades del medio académico local. Asimismo, resulta importante destacar en esta primera etapa las vicisitudes propias del concierto internacional que terminarían por definir un derrotero particular en los procesos económicos en nuestras latitudes nacionales. En este sentido, cabe resaltar la presencia de concesionarios locales (para el caso de los medicamentos) y de insumos médicos foráneos. Empero, el fenómeno de incipiente sustitución de importaciones pronto encontró su tope y no se prolongó más allá del final de la contienda ${ }^{39}$.

\section{8-1929: un mercado en transición}

${ }^{36}$ Revista de la Asociación Médica Argentina, Suplemento especialidades, Buenos Aires, -/-/ 1918, p.125.

${ }^{37}$ Revista de la Asociación Médica Argentina, Buenos Aires, -/6/1917, p. 151.

38 Revista de la Asociación Médica Argentina, Suplemento Especialidades, Buenos Aires, -/-/1918, p. 14.

39 Alejandro Cattaruzza. Historia de la Argentina. 1916-1955. Buenos Aires, Siglo XXI, 2012, p.92. 


\section{Dinámicas publicitarias en Argentina: una aproximación al caso de la Revista de la Asociación Médica Argentina (1914-1938)}

Los años inmediatamente posteriores a la finalización del conflicto bélico evidenciaron un claro crecimiento para la Argentina, tanto en términos per cápita como globales. Algunas muestras palpables de la renovada prosperidad de los años del gobierno de Alvear (1922-1928) son la distención social (las huelgas fueron menos, más calmas y muchas veces estuvieron relacionadas con conflictos gremiales internos antes que con reclamos por las condiciones de vida de los obreros) el aumento de los salarios reales, la disminución del desempleo, el crecimiento de la producción, las nuevas oleadas inmigratorias ${ }^{40}$, etc. De acuerdo con Gerchunoff y Llach, la desagregación del crecimiento muestra, que la importancia de las actividades industriales estaba en ascenso. Es que si bien en la década del 20' la vida económica nacional todavía giraba alrededor de la producción primaria, la relevancia del campo era cada vez menor respecto a la de la industria. En uno y otro sector, por estos años, se observa dinamismo, pero la tasa de crecimiento de las actividades manufactureras fue mayor que la del sector agropecuario, con lo que su participación en el producto global argentino aumentó ${ }^{41}$.

Ahora bien, este relativo despegue industrial nacional no es un proceso que podamos vislumbrar claramente a partir del estudio de las publicidades colocadas en la editorial en cuestión. De hecho, la cantidad de avisos de específicos/ casas comercializadoras argentinas bajó de diez a siete, al tiempo que aumentó (aunque no exponencialmente) la oferta farmacéutica de origen internacional (de cuatro pasaron a ser nueve). Algunos datos editoriales confirman nuestras observaciones, puesto que en el año 1927 la administración hace especial referencia a la búsqueda de colocación de una mayor cantidad de publicidades que viene desde el año anterior, proyecto cuya concreción se estaría dificultando -en principio- porque la editorial aún no lograba publicarse regularmente ${ }^{42}$. De acuerdo a los informes elaborados por el consejo de publicidad de la revista, podemos aseverar que este sería un problema que subsistiría hasta casi finales de los años 30'. No obstante los entramados señalados, debemos destacar que las dinámicas publicitarias de estos años nos permiten inferir que la industria farmacéutica nacional se hallaba más afianzada que en los precarios años de guerra.

En cuanto al ofrecimiento de medicamentos, en este segundo momento advertimos una mayor profusión de productos vinculados a la profilaxis y al cuidado de la salud; es decir, como se observa en las fotografías $8,9,10$ y 11, hay un marcado interés por preservar el estado saludable de la población ${ }^{43}$. Sin embargo, cabe remarcar que la industria farmacéutica aún no se encontraba orientada a la

\footnotetext{
40 Roberto Cortés Conde. La economía política de la Argentina en el siglo XX. Buenos Aires, Edhasa, 2007, pp.78-80.

41 Pablo Gerchunoff y Lucas Llach. El ciclo de la ilusión..., Op. Cit, pp. 80-90.

42 Revista de la Asociación Médica Argentina, Buenos Aires, -/1-4/1927, pp. 5-12.

43 Para mayor información, véase: María Isabel Garnino y Ana Virginia Persello. "La reformulación del mercado de atención médica, Buenos Aires, 1920-1940”. Anuario de Rosario, N13, 1988, pp. 343367.
} 


\section{María Dolores Rivero}

producción de medicamentos estrictamente destinados al tratamiento de enfermedades crónicas, fundamentalmente porque en este período las enfermedades infectocontagiosas todavía no perdían protagonismo en los índices de mortalidad.

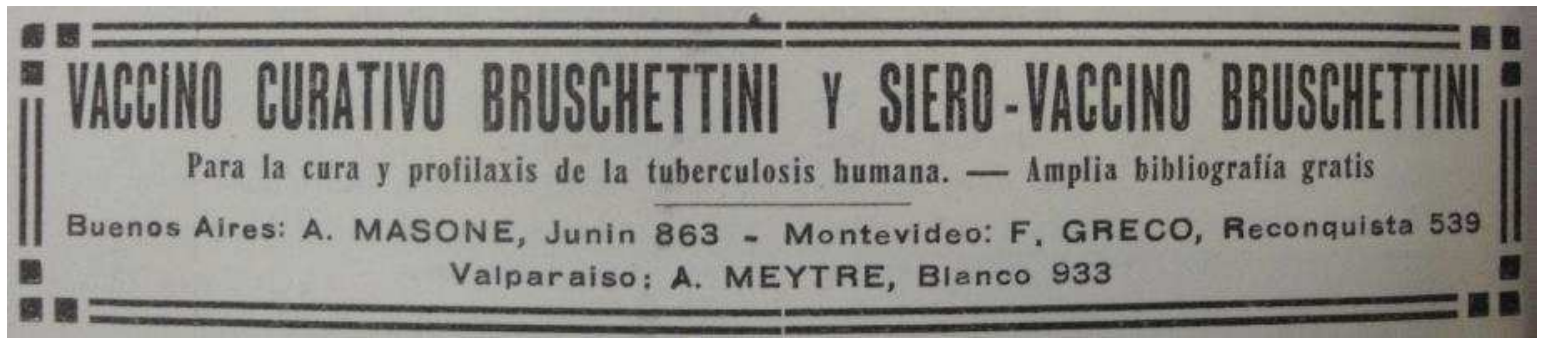

Fotografía 8: Bruschettini. Revista de la Asociación Médica Argentina. Suplemento especialidades, 1918, p.86.

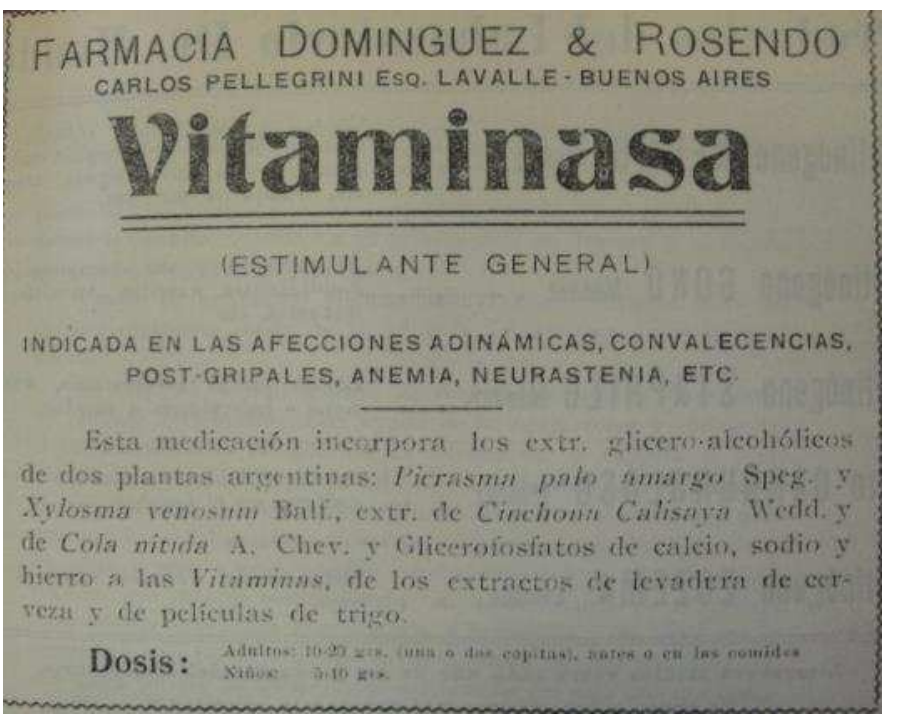

Fotografía 9: Vitaminasa. Revista de la Asociación Médica

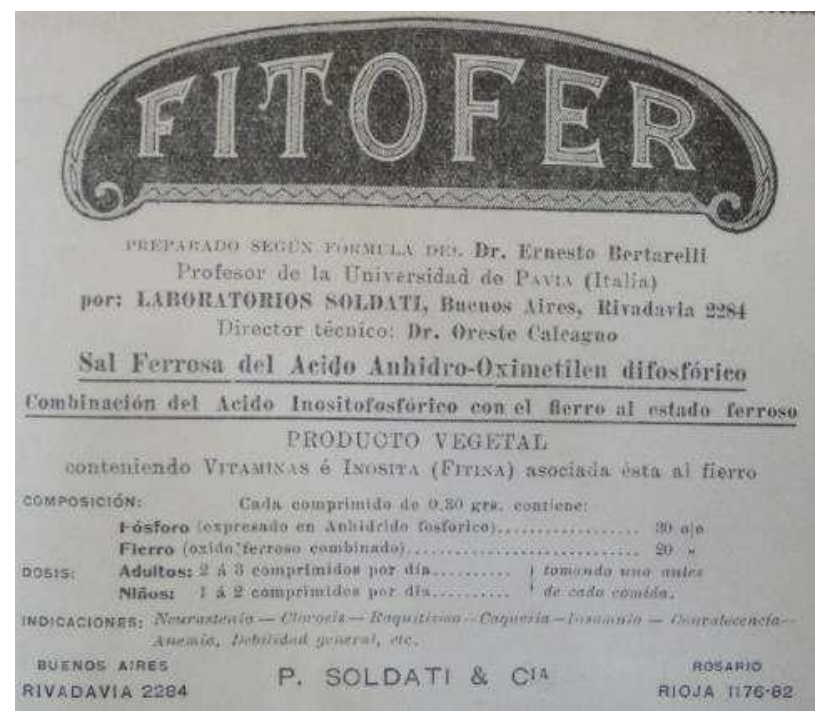

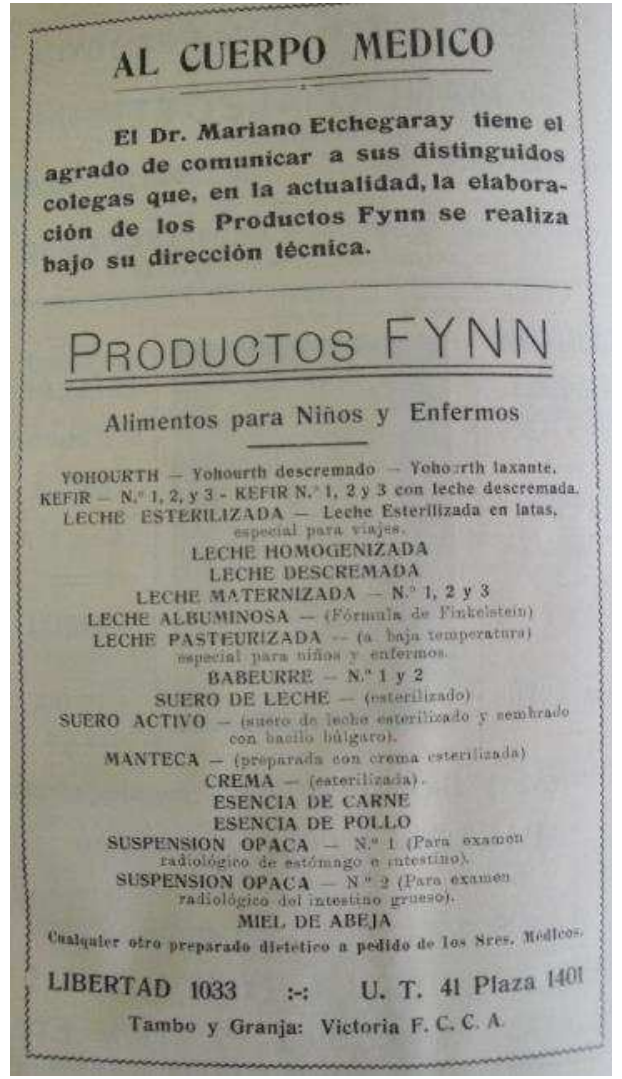

Argentina. XXXV. N $^{\circ} 213-214$.

Sección oftalmología, 1922, p. 437

Fotografía 10: Fynn.

Revista de la Asociación

Médica Argentina

Sección urología. XXXVI. $\mathrm{N}^{\circ} 229,1922, \mathrm{~s} / \mathrm{p}$. 


\title{
Dinámicas publicitarias en Argentina: una aproximación al caso de la Revista de la Asociación Médica Argentina (1914-1938)
}

\author{
Fotografía 11: Fitofer. Revista de la \\ Asociación Médica Argentina. \\ XXXV. N²13-214, 1922, s/p.
}

Retomando los orígenes nacionales de la oferta, se destacan tendencias de mixtura: entre algunos pocos medicamentos producidos en nuestras latitudes se encuentran aquellos promocionados por el Instituto Biológico Argentino ${ }^{44}$, la Vitaminasa, "medicación que incorpora los extractos glícero-alcohólicos de dos plantas argentinas"45, los "productos del laboratorio del $\mathrm{Dr}$ Méndez"46 y los elaborados en los laboratorios Delfino ${ }^{47}$.

Dentro del grupo de los medicamentos de origen internacional promocionados en la revista es posible entrever una importante presencia de laboratorios italianos en el medio local, como así también del personal especializado en su producción en nuestro país; la "Droguería Beretervide, Leonardini y Cia." (que dispensaba vacunas) ${ }^{48}$, el "Instituto Nacional Médico Farmacológico de Roma" (productor de los medicamentos Serono) ${ }^{49}$; el "Laboratorio Soldati" (que se apegaba a fórmulas químicas elaboradas por especialistas de la Universidad de Pavia) ${ }^{50}$ son un claro ejemplo de esta tendencia. Por otra parte, resulta insoslayable hacia el final de esta segunda etapa la aparición en escena de los productos Bayer. Recordemos que tras el conflicto bélico -con el Tratado de Versalles- se impuso sobre Alemania, Austria y sus aliados una pesada carga de reparaciones de guerra, entre una multitud de condiciones económicas y militares que los desfavorecían; en este escenario, las industrias alemanas debieron esperar algunos años hasta lograr reconstituirse y reubicarse en el mapa del mercado mundial ${ }^{51}$. El caso de Bayer no escaparía a esta tendencia y un sintético recorrido por su derrotero dará cuenta de ello.

El nombre de Bayer se conocía en la Argentina desde 1900, cuando comenzaron a importarse algunos de sus productos farmacéuticos. El crecimiento de la empresa y del propio país llevaron a que “... el 2 de enero de 1911 unos brillantes visionarios de origen alemán solicitasen, en el consulado argentino de Düsseldorf, el establecimiento de una sociedad mercantil, regular y colectiva, con

\footnotetext{
${ }^{44}$ Revista de la Asociación Médica Argentina, Sección oftalmología, Buenos Aires, -/-/1921, p.1053.

${ }^{45}$ Revista de la Asociación Médica Argentina, Sección oftalmología, Buenos Aires, -/-/1922, p.437.

${ }^{46}$ Revista de la Asociación Médica Argentina, Sección oftalmología, Buenos Aires, -/-/1921, p.1067.

47 Revista de la Asociación Médica Argentina, Buenos Aires,-/ 1-6/1924, p. 104.

48 Revista de la Asociación Médica Argentina, Sección oftalmología, Buenos Aires, -/-/1921, p.1053.

${ }^{49}$ Revista de la Asociación Médica Argentina, Sección oftalmología, Buenos Aires, -/-/1921, p.1067.

${ }^{50}$ Revista de la Asociación Médica Argentina, Buenos Aires, -/-/1922, s/p.

51 Magalí Romero Sá, y André Felipe Cândido da Silva. "La revista médica de Hamburgo y la revista germano-ibero-americana: diseminación de la medicina germánica en España y América Latina (1920-1933)". Asclepio, Revista de Historia de la Medicina y de la Ciencia, Vol. LXII, º 1, 2010, pp. 734.
} 


\section{María Dolores Rivero}

domicilio y asiento principal en la ciudad de Buenos Aires, capital de la República Argentina, que girará bajo la razón social de Federico Bayer y Compañía"52; es decir, diez años después de que sus productos comenzaran a comercializarse en la Argentina, Bayer inauguró una filial en Buenos Aires y al año siguiente, la empresa puso en marcha la primera prensa para fabricar Aspirina. La presencia de la Química Industrial Bayer en Argentina tras la Gran Guerra fue el más claro ejemplo de la búsqueda de reposicionamiento alemán en América Latina. Sin embargo, no sería hasta mediados de la década del 20' que haría su aparición estelar en el mercado examinado. Sería recién a partir de ese momento que la figura de Bayer se tornaría permanente en la revista desarrollando una amplia oferta medicamentosa como se puede ver en la fotografía 12.

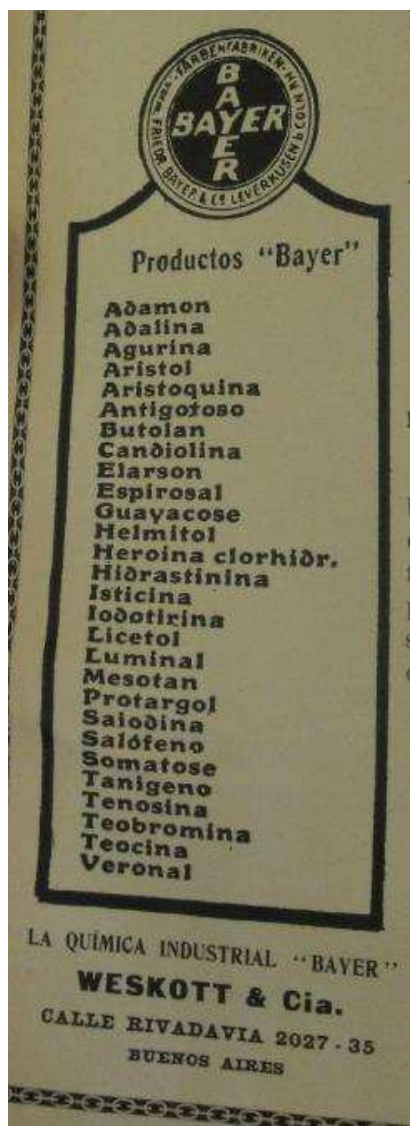

Fotografía 12: Bayer. Revista de la Asociación Médica Argentina. Sección nipiología. XXXVII. s/n, 1924, s/p.

Los insumos médicos también arrojarían luz acerca de ciertas matrices de heterogeneidad en cuanto a la procedencia de la oferta. Sin embargo, debemos resaltar la preponderancia de productos de origen internacional, tendencia que consideramos se imbricaría con un desarrollo aún incipiente de la industria argentina, fundamentalmente de aquella rama vinculada a la aparatología terapéutica. Asimismo, conviene resaltar que en relación a la etapa anterior, durante los años 20' se observa una clara profusión de publicidades de este tipo de productos, tal y como lo muestran las fotografías 13,14 y 15.

\footnotetext{
52Disponible en:http://www.bayer.com.ar/noticias/centenario argentina/centenario argentina01.php. [Consulta: 15/04/2017].
} 
Dinámicas publicitarias en Argentina: una aproximación al caso de la Revista de la Asociación Médica Argentina (1914-1938)

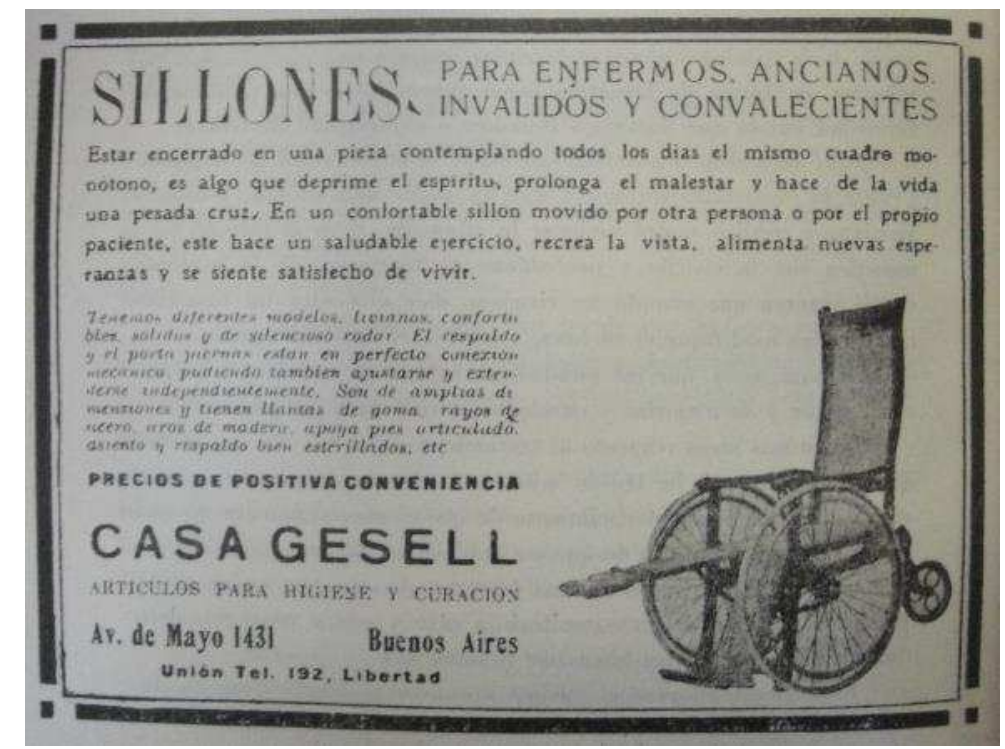

Fotografía 13: Casa Gesell. Revista de la Asociación Médica Argentina. XXXI, 1922, p.368

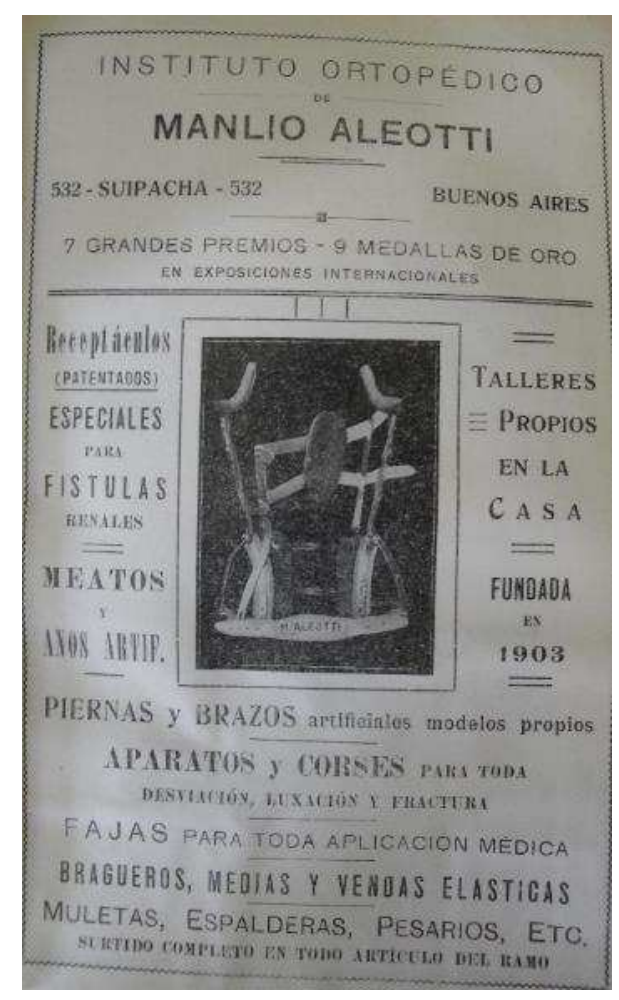

Fotografía 14: Manlio Aleotti.

Revista de la Asociación

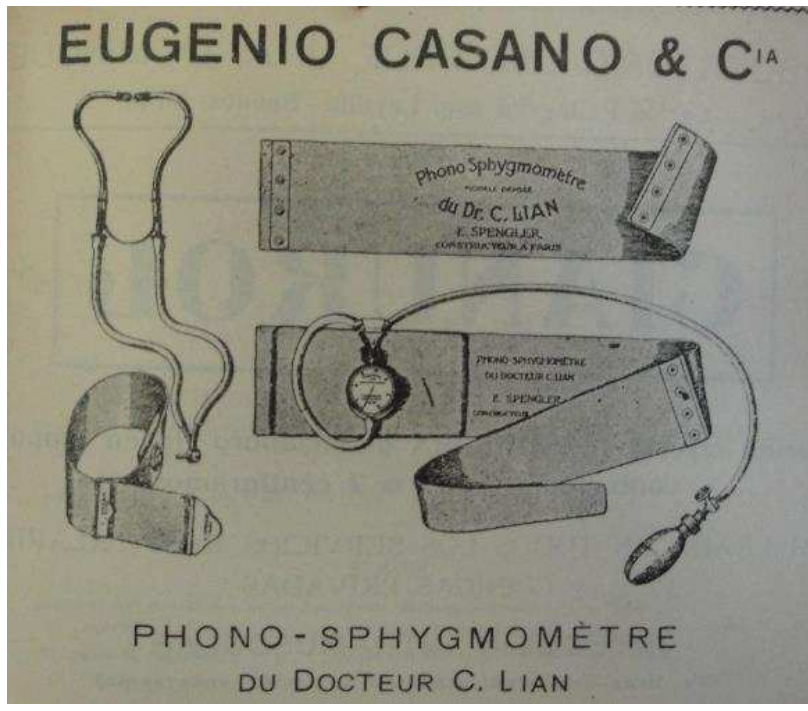

Fotografía 15: Casano. Revista de la Asociación Médica Argentina. Sección oftalmología. XXXIV. N²05, 1922, p. 1285. 


\title{
María Dolores Rivero
}

\author{
Médica Argentina. Sección \\ urología. XXXVI. N²27, 1922, \\ $\mathrm{s} / \mathrm{p}$.
}

El ofrecimiento de determinados insumos médicos especializados nos conduce a conjeturar que, por estos años, las especialidades médicas se hallaban mayormente delimitadas y desarrolladas, al menos en relación al momento publicitario anterior. Es que entre los productos ofertados se encuentran aquellos ligados a la ortopedia, la ginecología, la cardiología, etc. Por su parte, algunos indicadores editoriales también estarían dando cuenta de este fenómeno; en el año 1920 la revista lanza un comunicado en el que se anuncia que en a partir de los próximos números se incorporará un nuevo formato, correspondiente a la división en secciones de la editorial de acuerdo a un conjunto de especialidades médicas ${ }^{53}$. Esta modificación se sostendrá hasta el año 1924.

Las construcciones discursivas mostrarían ciertas luchas que aún se encontraban librando tanto las iniciativas comercializadoras nacionales como las internacionales por afianzar sus productos (tanto en el rubro de medicamentos como en el de los insumos) en el mercado; todavía intentaban convencer al potencial público lector especializado de la revista -que ya contaba con cierto grado de afianzamiento y legitimación social- de que prescribiera/utilizara sus "mercaderías". Esta tarea podía implicar desde referir a algún destacado profesional de la salud que estuviese implicado en la elaboración del producto o que simplemente lo utilizase/recetara frecuentemente, hasta mencionar la trayectoria del laboratorio sintetizador.

De manera convergente, observamos que persisten estrategias publicitarias que muestran un desplazamiento en el discurso; se continúa haciendo alusión, aunque sólo en algunas oportunidades, a la comodidad de determinados artefactos, el precio o el sabor, características que adquirirían interés para el paciente. Tal vez, la única que firma que escapara a estas tramas sería Bayer, por encontrarse desde hacía tiempo notoriamente reconocida y legitimada por la comunidad médica mundial.

Los años posteriores a la finalización de la Primera Guerra Mundial, entonces, se caracterizarían por una serie de mutaciones en la cartografía mundial; se asiste a una búsqueda constante de reacomodamiento y reafirmación de múltiples países en este nuevo escenario. Para la Argentina, la culminación de la contienda -en términos económicos- implicaría un crecimiento, particularmente de las actividades industriales, aunque las agrícolas no cesaron de ocupar un lugar de relativo protagonismo. En este sentido, se constata que la industria farmacéutica también habría comenzado a dar sus primeros pasos, pero aún se encontraba en un estadio embrionario. Esta tendencia se replicaría en el mercado examinado, en el cual observamos un pequeño aumento en la colocación de avisos respecto a la etapa

53 Revista de la Asociación Médica Argentina, Buenos Aires, -/-/ 1920, pp. 1-3. 


\section{Dinámicas publicitarias en Argentina: una aproximación al caso de la Revista de la Asociación Médica Argentina (1914-1938)}

anterior (hallándose sólo dos publicidades más que en la etapa anterior), pero no un notorio avance de las iniciativas argentinas, tanto en el grupo de los medicamentos como en el de los insumos médicos especializados; este momento, entonces, podría ser entendido en términos transicionales. La ampliación del mercado publicitario, como hemos visto, era un elemento que despertaba interés en los editores de la revista que, por estos años, no lograban aún regularizar su aparición.

\section{9-1938: un mercado publicitario en transformación. Hacia un estadio de consolidación}

La crisis de 1929 sobrevino dañando los sistemas económicos internacionales y el argentino. En este punto, conviene recordar que aunque el desempeño económico mundial durante la década del 20' no tuvo la solidez ni la universalidad características del periodo previo a 1914, varios países -entre los cuales debe incluirse a la Argentina- retomaron la senda del crecimiento que se había interrumpido durante la Primera Guerra Mundial. El comercio internacional, a pesar de estar amenazado por prácticas proteccionistas, recuperó algo de su brillo de la belle époque y Europa Occidental pudo reestablecerse en alguna medida al desastre de la guerra54 . Así, los Roaring Twenties dejaron en Estados Unidos el sabor de un progreso que parecía imparable y cuyos frutos eran compartidos por la sociedad entera. Sin embargo, muy pronto, el sueño del avance perpetuo se habría transformado en la pesadilla de la Gran Depresión ${ }^{55}$. Si bien desde la óptica de Gerchunoff y Llach el origen de la crisis está asociado a problemas internos en los Estados Unidos, pronto se pusieron en marcha mecanismos que transmitieron el problema al resto del mundo. Las caídas de demanda fueron propagándose al comercio mundial, cuyo volumen cayó alrededor de un 30\% entre 1929 y 1932 . En el intento por atenuar las consecuencias de la caída de la bolsa, cada país trató de evitar la competencia de importaciones extranjeras ${ }^{56}$.

La disminución del poder de compra de las exportaciones, la imposibilidad de comprimir a la misma velocidad las importaciones, el trastrocamiento de flujos de capitales extranjeros y el abandono de la libre transferibilidad de divisas plantearon problemas inéditos para los países de la periferia ${ }^{57}$. Como se mostró previamente, salvando la breve irrupción impuesta por la Gran Guerra, la conexión

\footnotetext{
${ }^{54}$ Pablo Gerchunoff y Lucas Llach. El ciclo de la ilusión..., Op. Cit, p. 110.

55 No hay un total acuerdo acerca de cuándo y dónde comenzó la crisis. Algunos la remontan al crack de la bolsa en New York el jueves negro de octubre de 1929, otros a la quiebra del Credit Anstaldt en Austria y su extensión a Alemania y a los países centrales con una gran salida de reservas que luego incidió en la fuerte presión sobre la libra que llevo a Gran Bretaña, en octubre de 1931, a abandonar el patrón oro. Sauvy sostiene que la crisis había empezado antes en Francia; Kindleberger afirma que su origen debe buscarse en la depresión agrícola de mediados de la década del 20' (Cortes Conde, 2007: 86).

56 Pablo Gerchunoff y Lucas Llach. El ciclo de la ilusión..., Op. Cit, p.112.

${ }^{57}$ Aldo Ferrer. La economía argentina. Desde sus orígenes hasta principios del siglo XXI. Argentina, Fondo de Cultura Económica, 2008, p. 245.
} 


\section{María Dolores Rivero}

económica de la Argentina con el resto del mundo era muy estrecha desde hacía décadas. Las exportaciones eran fundamentales no sólo para mantener altos los niveles de empleo y actividad en el país, sino además para importar aquellos bienes que Argentina no producía. Entre ellos no había sólo productos industriales de consumo; más importante aún, maquinaria y equipos necesarios para inversiones urbanas y rurales, y los insumos utilizados por una industria cada vez más desarrollada, representaban en 1929 tanto como un 63\% del total de importaciones ${ }^{58}$. En este marco, resulta evidente que la crisis del 29' trastocó irreparablemente la economía nacional y modificó sensiblemente su vinculación con el sistema internacional. Así, el nuevo funcionamiento del mercado mundial que se estableció tras la Gran Depresión impulsó un cambio lento, difícil al principio, en la organización productiva argentina, que comenzó a volcarse en parte hacia el mercado interno, jalonando un proceso conocido como Sustitución de Importaciones (en adelante ISI) ${ }^{59}$. A partir de ese momento, se redujeron sustancialmente las importaciones, factor crucial que hizo aumentar la producción manufacturera. Durante los años 30', entonces, estaríamos en presencia de un despegue industrial nacional que no sólo se vislumbraría en la expansión de la producción de tejidos de algodón, neumáticos, extracción y refinamiento de petróleo, conservas, aceites, sino también en el mayor desarrollo de la producción medicamentosa local, hecho que -conjeturamos- se vincularía con una nueva etapa en el mercado publicitario de medicamentos e insumos médicos especializados.

Diego Armus sostiene que en esta época se produjo una dinámica distintiva por la cual en el sector farmacéutico las concesiones de comercialización exclusiva se convirtieron en laboratorios, los que protegidos por la política aduanera propia de la década del 30', generaron las condiciones ideales para competir con la producción local 60 . De acuerdo a la bibliografía especializada, las inversiones europeas y norteamericanas (ya presentes desde la década del 20') a partir de los años 30' se reorientaron hacia la producción dirigida al mercado interno argentino ${ }^{61}$. No intentamos determinar cuáles fueron los laboratorios e iniciativas industriales nacionales que recibieron aportes de capitales extranjeros $\mathrm{y}$, desde las publicidades, no nos es posible identificar iniciativas de comercialización transformadas en laboratorios. Igualmente, aquellos procesos de movimiento de capitales y transformaciones organizacionales en el sector constituyeron el escenario desde donde entender el notorio aumento de las iniciativas de "producción nacional" desde los últimos años de la década del 20' y hasta el estallido de la Segunda Guerra, que -como veremos- competirían con las foráneas, las cuales también se hallarían en crecimiento. En otros términos, de acuerdo a la progresiva afirmación del proceso de industrialización nacional y sus políticas asociadas, suponemos que las dinámicas de afianzamiento de las publicidades de las iniciativas

\footnotetext{
58 Pablo Gerchunoff y Lucas Llach. El ciclo de la ilusión..., Op. Cit, pp. 112-113.

${ }^{59}$ Alejandro Rofman y José Luis Romero. Sistema socioeconómico..., Op. Cit, pp. 155-159.

${ }^{60}$ Diego Armus. La ciudad..., Op. Cit, p. 306.

${ }^{61}$ Alejandro Rofman y José Luis Romero. Sistema socioeconómico..., Op. Cit, pp. 171-172.
} 


\section{Dinámicas publicitarias en Argentina: una aproximación al caso de la Revista de la Asociación Médica Argentina (1914-1938)}

nacionales productoras y comercializadoras de medicamentos atravesaron un momento de avance a partir de fines de la década del 20' y comienzos de la siguiente, hasta aproximadamente 1938. Numéricamente, esta tendencia implicaría el paso a la aparición de diecinueve anuncios de carácter nacional en la revista. Por su parte, el sector de insumos médicos especializados, sin embargo, no mostraría las mismas tendencias. En este caso es posible observar un notorio descenso en términos cuantitativos.

El incremento de la colocación de avisos medicamentosos nacionales como internacionales es un fenómeno que, de acuerdo a nuestra perspectiva, podría estar asociado al crecimiento editorial. Es que a partir de comienzos de la década del 30', en la revista se observan nuevas estrategias de edición -vinculadas a la reducción de gastos-, mientras posteriormente se lograría realizar la tirada quincenal. Asimismo, se advierte un nuevo estilo "journal" (es decir, se apela a un formato de periódico, de tipo moderno) en el cual se incluye un apartado titulado "medicamentos nuevos". De esta manera, conjeturamos, la publicación se tornaría un espacio publicitario más atractivo, sobre todo para empresas alemanas y francesas, entre las cuales Bayer tendría un espacio protagónico. De manera convergente, entendemos que si bien la crisis de 1930 pareció ser un obstáculo en la evolución de la actividad publicitaria, esta avanzó en su modernización, pues se había vuelto indispensable para cualquier gran firma productora. Más que un freno al desarrollo de un campo profesional propio, la depresión económica sirvió para fortalecer a quienes aplicaban los métodos más vanguardistas en la indagación acerca de comportamientos de los consumidores en la respuesta a sus demandas ${ }^{62}$.

Aunque, como marcamos, es notoria y claramente visible la presencia y preponderancia de avisos de origen foráneo (en total, hemos registrado cuarenta y ocho avisos extranjeros), uno de los rasgos más sobresalientes de esta tercera etapa en el mercado publicitario estudiado es la consolidación de determinadas iniciativas nacionales que ya venían ofertando sus productos desde el periodo anterior. Así, se halla una importante cantidad de publicidades correspondientes al "Instituto Biológico Argentino", “CIBA” y el "Instituto Endocrinico Zimasa”. Si bien la mayor parte de los productos publicitados por estas empresas continúa formando parte del universo amplio de los sueros y las vacunas -tendientes a preservar el buen estado de salud de los individuos- en este período también observamos la producción de medicamentos vinculados a determinadas afecciones, entre las cuales se destacan aquellas de carácter sexual (impotencia), tuberculosis, sífilis, etc (ver fotografías $16,17$ y 18$)$.

62 Fernando Rocchi. "La sociedad de consumo en tiempos difíciles: el modelo estadounidense y la modernización de la publicidad argentina frente a la crisis de 1930". Historia Crítica, 1917, N 65, p. 110. 


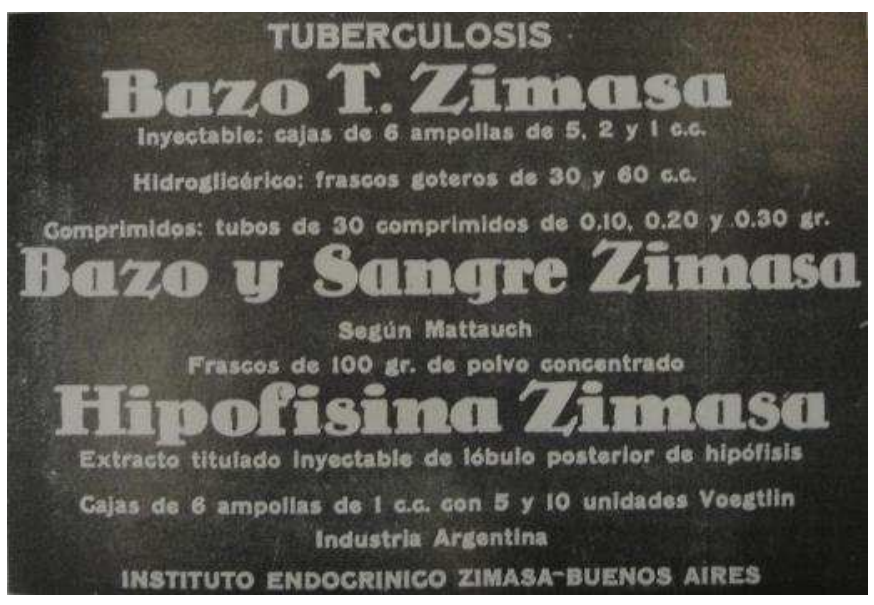

Fotografía 16: Zimasa. Revista de la Asociación Médica Argentina. Sección de dermatología y sifilografía, XLIX. N³44,1935, p. 399.

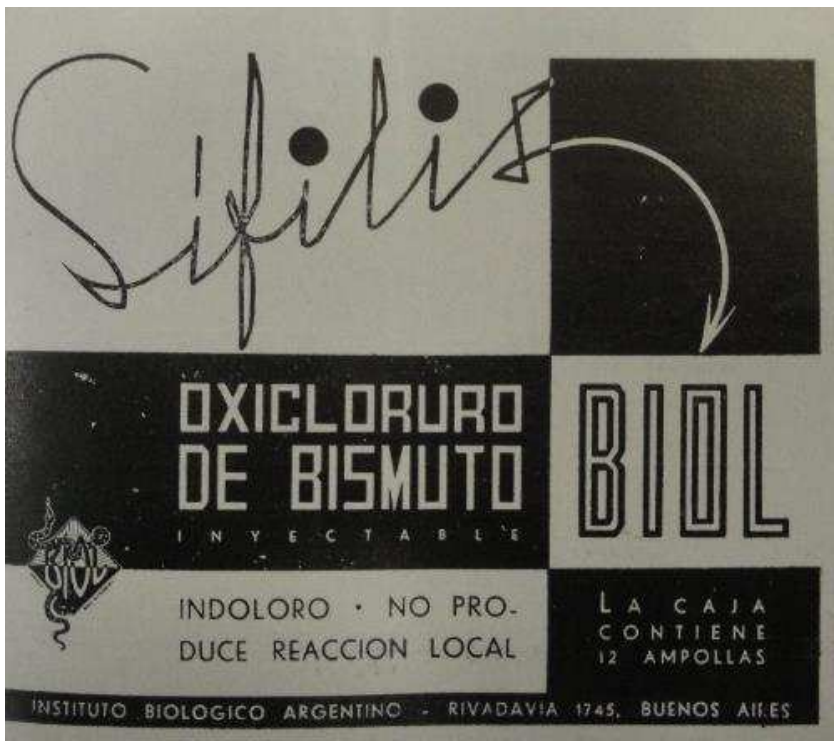

Fotografía 18: Biol. Revista de la Asociación Médica Argentina. Sección otorrinolaringología, XLIX. N³44, 1935, s/p.

Este elemento -la especificidad en cuanto a las enfermedades que combatían los medicamentos en cuestión- es otra arista fundamental de esta etapa del mercado examinado. No sólo en el caso de las ofertas nacionales, sino también de las internacionales que, incluso, en muchas oportunidades se encontrarían en un proceso de clara competencia entre sí. Un ejemplo de ello es la promoción de Laristina (de Roche, laboratorio de origen alemán), destinada a combatir las úlceras 


\section{Dinámicas publicitarias en Argentina: una aproximación al caso de la Revista de la Asociación Médica Argentina (1914-1938)}

gastrodudenales ${ }^{63}$; el extracto hepato-gástrico Serono (de origen italiano, también destinado a problemas gastrointestinales) ${ }^{64}$ y la Euboldina (producto alemán), prescrita en caso de afecciones hepáticas y estreñimiento crónico ${ }^{65}$.

Dentro de esta tendencia de marcada individualización de las dolencias que mitigaban los productos medicamentosos ofertados, resulta insoslayable el aumento sustantivo de avisos vinculados a enfermedades de carácter crónico, como las cardiopatías, encontrándonos para este período con nueve anuncios relativos a este tipo de afecciones. En este sentido, cabe subrayar que en Argentina, la gravitación de las muertes por enfermedades infecciosas sobre el total de las defunciones fue decreciendo a partir recién a partir de 1940, relacionada a los cambios experimentados por la población a través de un envejecimiento de su estructura por edad y también a los avances de la ciencia médica. La introducción de la sulfamida y la penicilina, el progreso de la provisión de agua potable y las políticas sociales y de salud -dentro de las cuales se encontraba la concientización social acerca de las normas higiénicas en el cuidado de los niños- y un andamiaje sanitario importante, constituyeron las causas principales de la reducción de las enfermedades infecto-contagiosas ${ }^{66}$. Todas estas variables se encontraron enmarcadas en procesos políticos más amplios y complejos; es que en los años cuarenta en la Argentina se desplegó un intenso proceso de construcción estatal que generaría nuevas capacidades de elaboración de políticas públicas e intervención social. A su vez, este fenómeno fue acompañado por una creciente centralización del poder político estatal en el Ejecutivo nacional ${ }^{67}$.

Ahora bien, como hemos señalado, el mercado publicitario analizado muestra rasgos de este proceso que venimos reseñando -en el cual se observan cambios en el perfil de morbi-mortalidad de la población- que indicarían que dichas mutaciones se habrían suscitado antes de lo comúnmente señala la bibliografía especializada. De acuerdo a esto, junto con Carbonetti y Celton, entendemos que resulta necesario referir al advenimiento de múltiples transiciones en Argentina durante el siglo XX ${ }^{68}$; es que si bien se estima que las defunciones por enfermedades infecto-contagiosas tuvieron mayor relevancia hasta 1960, década en que comienzan a perder importancia frente a las enfermedades cardio y cerebrovasculares, nuestro mercado mostraría otras tendencias. Asimismo, tempranamente observamos el inicio de la oferta de medicamentos orientados al tratamiento de enfermedades nerviosas, tales

\footnotetext{
${ }^{63}$ Revista de la Asociación Médica Argentina, Sección de dermatología y sifilografía, Buenos Aires,-/-/ 1935, s/p.

${ }^{64}$ Revista de la Asociación Médica Argentina, Sección oftalmología, Buenos Aires, -/-/1932, p. 255.

65 Revista de la Asociación Médica Argentina. Sección de tisiología, Buenos Aires,-/-/ 1935, p. 931.

${ }^{66}$ Adrián Carbonetti y Dora Celton. La transición..., Op. Cit, p. 391.

67 María José Ortiz Bergia. "La salud pública en transformación. La estructuración de políticas sanitarias en Córdoba-Argentina, 1930-1943". Asclepio. Revista de Historia de la Medicina y de la Ciencia, Vol. LXIV, N¹, 2012, 121- 146.

${ }^{68}$ Adrián Carbonetti y Dora Celton. La transición..., Op. Cit, p. 396.
} 


\section{María Dolores Rivero}

como "Neo- Neurene", "con potencia reforzada para el nerviosismo físico y moral"69. Por estos años, también hallamos el ofrecimiento de productos destinados a la cura de trastornos respiratorios (gripe, resfrio, pulmonías, neumonías), específicos de la piel, mientras no cesaba la aparición de anuncios de vacunas, presentes desde las etapas anteriores. Tal vez, la mayor novedad de este tercer momento lo constituyan los avisos publicitarios de "quimioterapias" para tuberculosis ${ }^{70}$, y para afecciones intestinales infecciosas ${ }^{71}$.

Estos rasgos de especialización en cuanto a la oferta de medicamentos que venimos refiriendo se imbricarían no sólo, como se marcó previamente, con los procesos de cambio en los patrones epidemiológicos de la población argentina. Consideramos que esa especificidad también se hallaría en correlación con las dinámicas de definición de las especialidades médicas que ya se encontraría, para la década de 1930, en marcado ascenso.

Entre 1929 y 1938, como hemos visto, las iniciativas nacionales medicamentosas adquirieron un relativo protagonismo respecto a los momentos publicitarios anteriores, hecho que nos permite referir a un proceso de consolidación del mercado. Los productos argentinos, entonces, ingresarían en una suerte de competencia con las iniciativas foráneas, fundamentalmente francesas y alemanas, mientras se observan procesos propios de la modernidad, tales como la urbanización, la modernización de la agricultura, la industrialización, que terminarían por determinar ciertas mutaciones en las condiciones de salud de las poblaciones. Estas condiciones definirían la primacía de la oferta de productos tendientes a combatir enfermedades crónicas, como las cardiovasculares. Convergentemente, estos entramados se asociarían a dinámicas de profesionalización médica que arrojarían luz acerca de un momento de consolidación y especialización de diferentes ramas de la medicina.

\section{Consideraciones finales}

En la presente indagación nos hemos interrogado por el proceso de conformación de un mercado de publicidades entre 1914 y 1938. Para ello, hemos procurado articular su análisis poniendo en tensión el proceso económico y de política económica nacional en relación a las dinámicas industriales y sus vinculaciones con el concierto internacional. Fue fundamental para esto considerar las tensiones y las pugnas propias del conflicto bélico y la entreguerra. Asimismo, colocamos bajo estudio ciertos entramados textuales desarrollados en distintos avisos para posicionarse en un mercado competitivo y dirigido a un público

\footnotetext{
${ }^{69}$ Revista de la Asociación Médica Argentina. Sección de anatomía normal y patológica, Buenos Aires,/-/ 1937, p. 334.

${ }^{70}$ Revista de la Asociación Médica Argentina, Sección de tisiología, Buenos Aires, -/-/1937, p. 32

${ }^{71}$ Revista de la Asociación Médica Argentina, Sección Sociedad Médica de La Plata, Buenos Aires, -//1935: s/p.
} 


\section{Dinámicas publicitarias en Argentina: una aproximación al caso de la Revista de la Asociación Médica Argentina (1914-1938)}

especializado, potencialmente definido por los profesionales médicos de Buenos Aires y otras ciudades de la Argentina. De acuerdo con ello, hemos intentado no perder de vista las relaciones entre los discursos publicitarios y los distintos momentos históricos de consolidación de la elite médica local.

El universo empírico estuvo constituido por una amplia selección de publicidades de productos farmacéuticos y de insumos médicos especializados (tecnología médica) colocadas en Revista de la Asociación Médica Argentina. La identificación de distintos rasgos nos ha permitido entrever una serie de ritmos que terminarían por definir períodos en la conformación de ese mercado de publicidades, momentos clave que han estructurado nuestra exposición. Así, hemos planteado la existencia de una primera etapa, delimitada entre 1914 y 1918; por estos años, no encontramos una profusa cantidad ni variedad de avisos, hecho que nos ha llevado a conjeturar un momento inicial en la constitución del mercado, en el cual advertimos un perfil notoriamente cientificista de la revista. Sin embargo, no debemos soslayar la presencia de algunos concesionarios locales (para el caso de los medicamentos) y de insumos médicos foráneos. Consideramos que las vicisitudes propias del concierto internacional marcaron un derrotero particular en los procesos económicos en nuestras latitudes nacionales, que durante los años de contienda -en términos de desarrollo industrial- resultaron incipientes. Convergentemente, estas dinámicas incidirían en la colocación de anuncios, como así también aquellas ligadas al proceso de profesionalización médica que habría comenzado a mediados del siglo XIX en nuestro país, pero que aún en los albores del siglo XX no terminaba de concretarse.

Entre fines de la Gran Guerra y la Gran Depresión asistiríamos a un segundo momento en el cual el mercado estudiado atravesó una transformación, tendiente a su posterior consolidación. En términos generales, podemos decir que en relación a la etapa anterior advertimos un pequeño crecimiento en la cantidad de avisos publicitarios, tendencia en la que habrían ido ganando protagonismo los avisos de iniciativas internacionales. Así, la ampliación del mercado, como hemos visto, era un elemento que despertaba interés y preocupación en los editores de la revista que, por estos años, no lograban aún regularizar su aparición. Esta etapa, entonces, podría ser entendida en términos transicionales y con características de mixtura, en cuanto a los orígenes nacionales de los productos farmacéuticos ofertados y a las enfermedades que estaban destinados a tratar.

Por su parte, los insumos médicos también arrojarían luz acerca de ciertas matrices de heterogeneidad en cuanto a la procedencia de la oferta. Empero, debemos resaltar la preponderancia de productos de origen internacional, tendencia que consideramos se imbricaría con el ya referido estadio incipiente de la industria argentina. Asimismo, hemos advertido una gran variedad de productos tecnológicos ofertados, hecho que, entendemos, se imbricaría con que las especialidades médicas se hallaban mayormente delimitadas y desarrolladas, al menos en relación al momento publicitario anterior. 


\section{María Dolores Rivero}

En una tercera etapa, que hemos delimitado entre fines de la década del 20' y 1938, las publicidades de las iniciativas nacionales productoras y comercializadoras de medicamentos atravesaron un proceso de avance, mientras el sector de insumos médicos especializados no mostraría las mismas tendencias. Convergentemente, hemos observado la consolidación de determinadas iniciativas nacionales que ya venían ofertando sus productos desde el periodo anterior. Entendemos que este fenómeno iría de la mano con la progresiva afirmación del proceso de industrialización nacional, que permitiría expandir y ampliar la producción medicamentosa local; sin embargo, la industria argentina aún no se encontraba lo suficientemente desarrollada como para comenzar a generar aparatología terapéutica en nuestras latitudes por la complejidad de dicha empresa. Claro que, no podemos soslayar que por estos años también observamos un aumento en la colocación de avisos publicitarios de laboratorios internacionales.

Esta mayor aparición de oferta medicamentosa podría asociarse a un crecimiento editorial. Es que en este momento, como hemos visto, la revista adquirió un nuevo estilo, se plantearon nuevas estrategias de edición, al tiempo que se logró realizar la tan anhelada tirada quincenal. Finalmente, y en relación a los productos ofertados, en esta etapa advertimos una mayor especificidad en cuanto a las enfermedades que combatían los medicamentos en cuestión, hecho que nos remitió a interrogarnos acerca de los procesos de profesionalización y especialización médica que, por aquellos años, se encontrarían avanzados. Particularmente -y en el marco de esta individualización de las dolencias que mitigaban los productos medicamentosos ofertados- hemos destacado el aumento sustantivo de avisos vinculados a dolencias de carácter crónico (como las cardiopatías), considerando que esta tendencia se encontraría en consonancia con los cambios en el perfil de morbi-mortalidad de la población, fenómeno que el mercado analizado no podía eludir.

\section{Bibliografía}

Armus, Diego. La Ciudad Impura. Salud, Tuberculosis y Cultura en Buenos Aires, 18701950. Buenos Aires, Edhasa, 2007.

Armus, Diego. “¿Qué historia de la salud y la enfermedad?”. Salud Colectiva, Vol. VI, $\mathrm{N}^{\circ} 1,2010$, pp. 5-10.

Armus, Diego. "Medicina casera, remedios y curanderos en los inicios de la medicalización de la ciudad moderna. Buenos Aires, 1870-1940". Tempos Históricos, XX, 2016, pp. 47-80.

Biernat, Carolina y Simonetto, Patricio "Provisión pública y oferta privada de medicamentos contra las enfermedades venéreas. Argentina 1930-1945". Revista Ciencias de la Salud, Vol. XV, N²2, 2017, pp. 273-291. 


\section{Dinámicas publicitarias en Argentina: una aproximación al caso de la Revista de la Asociación Médica Argentina (1914-1938)}

Caldo, Paula. Mujeres cocineras. Hacia una historia sociocultural de la cocina, Argentina a fines del siglo XIX y primera mitad del XX. Rosario, Prohistoria, 2009.

Campins, Mónica y Pfeiffer, Ana. "La importancia de las redes sociales en los orígenes de la industria farmacéutica argentina. El caso de los catalanes en Argentina". Revista de Historia Industrial, Nro. 47,2011, pp. 17-50.

Carbonetti, Adrián y Celton, Dora. "La transición epidemiológica", en Susana Torrado, (compiladora), Población y bienestar en la Argentina del primero al segundo centenario. Una historia social del siglo XX. Buenos aires, EDHASA, 2007.

Carbonetti, Adrián y Rodríguez, María Laura. "Las epidemias de cólera en Córdoba a través del periodismo: la oferta de productos preservativos y curativos durante la epidemia de 1867-1868”. Hist. cienc. saude-Manguinhos, Vol. XIV, № 2, 2007, pp. 405-419.

Carbonetti, Adrián. "Ofrecimiento de productos en épocas de epidemia. La publicidad en momentos de la pandemia de "gripe española" en Argentina, 1918 1919", en Miguel Ángel Cuenya y Rosalina Estrada Urroz, (compiladores), Nuevas miradas desde América Latina y México. Enfermedad y control social. Siglos XIX y XX. México, Instituto de Ciencias Sociales y Humanidades de la benemérita Universidad Autónoma de Puebla, 2013, pp. 147-167.

Cattaruzza, Alejandro. Historia de la Argentina. 1916-1955. Buenos Aires, Siglo XXI, 2012.

Coni, Emilio. Memorias de un médico higienista (Contribución a la historia de la higiene pública y social). Buenos Aires, A. Flaiban, 1918.

Cortés Conde, Roberto. La economía política de la Argentina en el siglo XX. Buenos Aires, Edhasa, 2007.

Cosse, Isabella. Mafalda: historia social y política. Buenos Aires, Fondo de Cultura Económica, 2010.

Elena, Eduardo. Dignifying Argentina: Peronism, Citizenship, and Mass Consumption. Pittsburgh, University of Pittsburgh Press, 2011.

Fernández, Sandra. La revista EL Círculo o el arte de papel Una experiencia editorial en la Argentina del Centenario. Murcia, Universidad de Murcia, 2010.

Ferrer, Aldo. La economía argentina. Desde sus orígenes hasta principios del siglo XXI. Argentina, Fondo de Cultura Económica, 2008. 


\section{María Dolores Rivero}

García, Juan César. "Historia de las instituciones de investigación en salud en América Latina, 1880-1930”. Educ Med Salud, Vol. XV, Nº 1, 1981, pp.71-88.

Garnino, María Isabel y Persello, Ana Virginia. "La reformulación del mercado de atención médica, Buenos Aires, 1920-1940”. Anuario de Rosario, № 13, 1988, pp. 343-367.

Gerchunoff, Pablo y Llach, Lucas. El ciclo de la ilusión y el desencanto. Un siglo de políticas económicas argentinas. Argentina, Ariel, 2010.

González Leandri, Ricardo. “Asociacionismo y representación de intereses médicos en Buenos Aires, 1852-1880". Asclepio. Revista de Historia de la Medicina y de la Ciencia, Vol. L, N² 2, 1998, pp.187-203.

Guglielminetti, Armando. "Jornadas Homenaje al $120^{\circ}$ Aniversario de la Revista de la Asociación Médica Argentina”. Revista de la Asociación Médica Argentina, Vol. CXXVI, N³, 2013, p. 7

Lincoln, Bailey. Morbilidad y mortalidad en la edad preescolar. Buenos Aires, Aniceto López, 1934.

Lluch, Andrea. Las manos visibles del mercado: Intermediarios y consumidores en la Argentina (Siglos XIXY XX). Rosario, Prohistoria, 2015.

Manzano, Valeria. The Age of Youth in Argentina: Culture, Politics, and Sexuality from Perón to Videla. Chapel Hill, The University of North Carolina Press, 2014.

Milanesio, Natalia. Cuando los trabajadores salieron de compras: nuevos consumidores, publicidad y cambio cultural durante el primer peronismo. Buenos Aires, Siglo XXI, 2014.

Múgica, María Luisa. “'Males vergonzantes' y prostitución reglamentada. Rosario, Argentina (1874-1932)". Asclepio. Revista de Historia de la Medicina y de la Ciencia, Vol. LXVIII, N², 2016, pp. 1-18.

Ortiz Bergia, María José. "La salud pública en transformación. La estructuración de políticas sanitarias en Córdoba-Argentina, 1930-1943”. Asclepio. Revista de Historia de la Medicina y de la Ciencia, Vol. LXIV, №1, 2012, 121- 146.

Otero, Hernán. Estadística y Nación. Una historia conceptual del pensamiento censal de la Argentina moderna. 1869-1914. Buenos Aires, Prometeo, 2006.

Pérez, Inés. El hogar tecnifcado: familias, género y vida cotidiana. Buenos Aires, Biblos, 2012. 


\section{Dinámicas publicitarias en Argentina: una aproximación al caso de la Revista de la Asociación Médica Argentina (1914-1938)}

Piglia, Melina. Autos, rutas y turismo: el automóvil club argentino y el estado. Buenos Aires Siglo XXI, 2014.

Pite, Rebekah. Creating a common table in twentieth-century Argentina: Doña Petrona, Women and Food. Chapel Hill,The University of North Carolina Press, 2013.

Remedi, Fernando. Dime qué comes y cómo lo comes y te diré quién eres. Una historia social del consumo alimenario en la modernización argentina. Córdoba, 1870-1930. Córdoba, Centro de Estudios Históricos "Prof. Carlos S. A. Segreti”, 2006.

Rocchi, Fernando. "Consumir es un placer: la industria y la expansión de la demanda en Buenos Aires a la vuelta del siglo pasado". Desarrollo Económico, V. 37, № 148, 1998, pp. 533-558.

Rocchi, Fernando. "Inventando la soberanía del consumidor: publicidad, privacidad y revolución del mercado en la Argentina (1860-1940)", en Fernando Devoto y Marta Madero (compiladores), Historia de la vida privada en la Argentina. Buenos Aires, Taurus, 1999, pp. 201-322.

Rocchi, Fernando. "La americanización del consumo: las batallas por el mercado argentino, 1920-1945”, en María Inés Barbero y Andrés Regalsky (editores), Estados Unidos y América Latina en el siglo XX. Transferencias económicas, tecnológicas y culturales. Buenos Aires, UNTREF, 2003, pp. 131-189.

Rocchi, Fernando. Chimneys in the Desert. Industrialization in Argentina during the Export Boom Years, 1870-1930. Chapel Hill, Stanford University Press, 2006.

Rocchi, Fernando. "La sociedad de consume en tiempos difíciles: el modelo estadounidense y la modernización de la publicidad argentina frente a la crisis de 1930". Historia Crítica, №65, 2017, pp. 93-114.

Rodríguez María Laura; Carbonetti, Adrián; Rizzi, Gastón y Rivero Dolores. "El mercado de las publicidades de medicamentos e insumos médicos especializados en el interior de Argentina: el caso de la «revista del Círculo Médico de Córdoba» y la «Revista Médica de Córdoba», Argentina, 1912-1938". Asclepio. Revista de Historia de la Medicina y de la Ciencia, Vol. LXVI, N², pp. 1-16.

Rofman, Alejandro y Romero, Luis. Sistema socioeconómico y estructura regional en la Argentina. Buenos Aires, Amorrortu, 1997.

Romero Sá, Magali y da Silva, André Felipe Cândido. "La revista médica de Hamburgo y la revista germano-ibero-americana: diseminación de la medicina germánica en España y América Latina (1920-1933)". Asclepio, Revista de Historia de la Medicina y de la Ciencia, Vol. LXII, N 1, 2010, pp. 7-34. 


\section{María Dolores Rivero}

Strasser, Susan. "Making consumption conspicuous: transgressive topics go mainstream". Tecnology and Culture, Vol. V, N 43, 2002, pp. 755-770.

\section{Consultas Online}

http://www.bayer.com.ar/noticias/centenario argentina/centenario argentina01. php [Consulta: 15/04/2017].

\section{Fuentes}

Revista de la Sociedad Médica Argentina

Revista de la Asociación Médica Argentina

Recibido: 20/08/2017

Evaluado: $15 / 09 / 2017$

Versión Final: 17/11/2017 